\title{
Evolution of Network Synchronization during Early Epileptogenesis Parallels Synaptic Circuit Alterations
}

\author{
(D) Kyle P. Lillis, ${ }^{1,2}$ Zemin Wang, ${ }^{1,2}$ Michelle Mail, ${ }^{1,2}$ Grace Q. Zhao, ${ }^{3}$ Yevgeny Berdichevsky, ${ }_{4}$ Brian Bacskai, ${ }^{1,2}$ \\ and $\odot$ Kevin J. Staley ${ }^{1,2}$ \\ ${ }^{1}$ Massachusetts General Hospital, Department of Neurology, Boston, Massachusetts 02114, ${ }^{2}$ Harvard Medical School, Boston, Massachusetts 02115, \\ ${ }^{3}$ Stanford University, Department of Neurobiology, Stanford, California 94305, and ${ }^{4}$ Lehigh University, Department of Electrical and Computer \\ Engineering, Bethlehem, Pennsylvania 18015
}

In secondary epilepsy, a seizure-prone neural network evolves during the latent period between brain injury and the onset of spontaneous seizures. The nature of the evolution is largely unknown, and even its completeness at the onset of seizures has recently been challenged by measures of gradually decreasing intervals between subsequent seizures. Sequential calcium imaging of neuronal activity, in the pyramidal cell layer of mouse hippocampal in vitro preparations, during early post-traumatic epileptogenesis demonstrated rapid increases in the fraction of neurons that participate in interictal activity. This was followed by more gradual increases in the rate at which individual neurons join each developing seizure, the pairwise correlation of neuronal activities as a function of the distance separating the pair, and network-wide measures of functional connectivity. These data support the continued evolution of synaptic connectivity in epileptic networks beyond the latent period: early seizures occur when recurrent excitatory pathways are largely polysynaptic, while ongoing synaptic remodeling after the onset of epilepsy enhances intranetwork connectivity as well as the onset and spread of seizure activity.

Key words: calcium imaging; homeostasis; network; two-photon

\section{Introduction}

Post-traumatic epilepsy is increasingly being recognized as an important public health problem (Ferguson et al., 2010; Raymont et al., 2010). We know very little about the processes that underlie the development of epilepsy after brain injury (Lowenstein, 2009; Noebels et al., 2012; Pitkänen and Immonen, 2014), and thus cannot develop rational treatments for this particularly refractory form of secondary epilepsy (Temkin, 2009; Prince et al., 2012; Goldberg and Coulter, 2013).

Computer modeling studies (Houweling et al., 2005) and hippocampal slice culture experiments (Bausch et al., 2006) have proposed that epileptogenesis could be driven by neuronal homeostasis, the process by which neurons normalize their input in the face of experience-dependent changes in synaptic weighting (Turrigiano et al., 1998; Pozo and Goda, 2010). The resultant networks may have different architecture than the networks built during normal development. For example, small-world networks, in which a minority of neurons are connected to an out-

\footnotetext{
Received Sept. 17, 2014; revised May 11, 2015; accepted May 15, 2015.

Author contributions: K.P.L. and K.J.S. designed research; K.P.L., Z.W., and M.M. performed research; G.Q.Z. and B.B. contributed unpublished reagents/analytic tools; K.P.L., Z.W., Y.B., and K.J.S. analyzed data; K.P.L. and K.J.S. wrote the paper.

This work was supported by the National Institutes of Health grants NS034700, NS074772, and NS077908 (to K.S.), and EB000768 (to B.B.).

The authors declare no competing financial interests.

Correspondence should be addressed to Kevin J Staley, 114 16th Street, \#2600, Charlestown, MA 02129. E-mail: staley.kevin@mgh.harvard.edu.

DOI:10.1523/JNEUROSCI.4007-14.2015

Copyright $\odot 2015$ the authors $\quad 0270-6474 / 15 / 359920-15 \$ 15.00 / 0$
}

sized number of other neurons (Watts and Strogatz, 1998), are a robust means by which to engender seizures (Netoff et al., 2004; Dyhrfjeld-Johnsen et al., 2007).

Anatomical studies demonstrate loss of principal cells, interneurons, and astrogliosis in experimental and human epilepsy (Buckmaster and Dudek, 1997; Maglóczky and Freund, 2005; Clasadonte and Haydon, 2012; Huusko et al., 2015). Axon sprouting is strongly correlated with epileptogenesis, although whether sprouting is necessary for epilepsy has been questioned (Heng et al., 2013). Similarly, loss of interneurons correlates poorly with subsequent epilepsy (Huusko et al., 2015), and in at least some models inhibition recovers by the time seizures commence (Thind et al., 2010).

The time course of epileptogenesis has been quantified by studying the frequency of spontaneous seizures after brain injury induced by status epilepticus (Williams et al., 2009). Seizure probability continues to increase after the first spontaneous seizure, implying that the processes underlying epileptogenesis continue after the first spontaneous seizures. Human data support the ongoing evolution of epilepsy (Elwes et al., 1988), including progressive regional atrophy (Bernhardt et al., 2013); the gradual emergence of drug resistance (Berg et al., 2006); and recrudescence of seizures years after seizure surgery (McIntosh et al., 2004, 2012).

The development of pathological synchronization during epileptogenesis is unexplored. Spikes precede seizures, but spikes do not increase in duration to become seizures (Williams et al., 2009, White et al., 2010). The topology of network synchronization 
remains hypothetical. For example, seizures could coalesce from smaller scattered nodes of physiological (Ikegaya et al., 2004; Bonifazi et al., 2009) or pathological (Huberfeld et al., 2011; Sabolek et al., 2012) synchrony. Alternatively, the fraction of neurons in the network participating could increase regardless of spatial constraints.

The organotypic hippocampal slice preparation provides an experimentally accessible preparation in which to study posttraumatic epileptogenesis (McBain et al., 1989; Berdichevsky et al., 2012; Albus et al., 2013). By visualizing neural activity during epileptogenesis, we can address questions regarding network structure and the evolution of pathological synchronization. We sequentially imaged, in the same slice cultures, the calcium activity of neurons throughout the early course of epilepsy.

\section{Materials and Methods}

Organotypic slice cultures. Organotypic slice culture protocols were approved by the Massachusetts General Hospital Subcommittee on Research Animal Care. For imaging experiments, membrane interface type organotypic slice cultures were prepared as described previously (Stoppini et al., 1991) from mice expressing Yellow Cameleon 3.6 in all Nestinpositive cells. Briefly, isolated hippocampi from P5-P8 pups of either sex were cut into $400 \mu \mathrm{m}$ slices on a Mcllwain tissue chopper (Mickle Laboratory Engineering). Slices were plated on membrane culture inserts (PICMORG50; Millipore) and placed in $50 \mathrm{~mm}$ coverslip glass-bottom Petri dishes (Fig. 1A; HBST-5040; WillCo Wells). For electrophysiological experiments, to facilitate transfer of sample to an electrode-accessible recording chamber, roller tube cultures were prepared, from C57BL/6 mice (patch-clamp experiments) or Sprague Dawley rats (kynurenate washout experiment) of either sex, on glass coverslips as previously described (Gähwiler, 1981; Dyhrfjeld-Johnsen et al., 2010). Cultures were incubated at $5 \% \mathrm{CO}_{2}, 36^{\circ} \mathrm{C}$ in $1.5 \mathrm{ml}$ Neurobasal-A growth medium with $2 \% \mathrm{~B} 27,500 \mu \mathrm{M}$ GlutaMAX, and $0.03 \mathrm{mg} / \mathrm{ml}$ gentamycin added (all from Invitrogen). Growth medium was changed every $3-4 \mathrm{~d}$. All imaging and loose-patch recordings were made in growth medium.

Electrophysiology. Organotypic slice cultures were transferred to a submerged recording chamber and perfused $(2.5 \mathrm{ml} / \mathrm{min})$ with prewarmed $\left(36^{\circ} \mathrm{C}\right)$ oxygenated $\left(95 \% \mathrm{O}_{2}\right.$ and $\left.5 \% \mathrm{CO}_{2}\right)$ ACSF containing the following (in mM): $119 \mathrm{NaCl}, 1.25 \mathrm{NaH}_{2} \mathrm{PO}_{4}, 3 \mathrm{KCl}, 26 \mathrm{NaHCO}_{3}, 11$ glucose, $2.5 \mathrm{CaCl}_{2}$, and $2 \mathrm{MgSO}_{4} .7 \mathrm{H}_{2} \mathrm{O}$, pH 7.4, for 30 min before electrophysiological recording. Recording electrodes were pulled from borosilicate glass capillaries (Sutter Instruments) using a micropipette puller (Model P-97; Sutter Instruments) with resistance $4-7 \mathrm{M} \Omega$ when filled with internal solution containing the following (in $\mathrm{mM}$ ): 120 CsGluconate, $5 \mathrm{MgCl}_{2}$, 0.6 EGTA, 30 HEPES, $4 \mathrm{Mg}$-ATP, $0.4 \mathrm{Na}_{2}$-GTP, 10 phosphocreatine-Tris, and 5 QX-314; $290 \mathrm{mOsm}$ and $\mathrm{pH}$ was adjusted at 7.2 with $\mathrm{C}_{\mathrm{S}} \mathrm{OH}$. Dual whole-cell patch-clamp recordings were made from a pair of CA1 pyramidal neurons with visualization using infrared differential interference contrast camera on an upright Nikon Eclipse FN1 microscope. Signal acquisition was performed using a Multiclamp amplifier (Multiclamp 700B; Molecular Devices) with Clampex 10 software (Molecular Devices). Signals were sampled at $10 \mathrm{kHz}$ and filtered at $2 \mathrm{kHz}$. Data were stored on a PC for off-line analysis after digitization by A/D converter (Digidata 1440A; Molecular Devices). The resting membrane potential of neurons was measured in current-clamp mode within $5 \mathrm{~s}$ of establishing whole-cell recordings to minimize the effect of internal solution on intrinsic properties of neurons. Membrane potential was corrected for a liquid junction potential of $13.7 \mathrm{mV}$. Neurons with resting membrane potential less than $-60 \mathrm{mV}$ were discarded. Neuronal input and access resistances were repetitively monitored during the experiment. Cells with changes of input and access resistance changes of $>20 \%$ were excluded from analysis.

Spontaneous EPSCs (sEPSCs) were collected at a holding potential of $-70 \mathrm{mV}$, which is close to the calculated (in whole-cell configuration, EGABA is heavily influenced by electrode $\mathrm{Cl}^{-}$concentration) reverse potential of GABA, which is $-68 \mathrm{mV}$. sIPSCs were also measured in the same neuron by raising the holding potential to $0-10 \mathrm{mV}$, a potential close to the reverse potential of excitatory input, to minimize the amplitude of concurrent sEPSCs. mEPSCs and mIPSCs were recorded from the same neurons after TTX $(1 \mu \mathrm{M})$ application for 30 min. Postsynaptic currents were detected using custom software (DClamp; www.ieeg.org/?q=node/34).

Loose-patch recordings were performed by sealing a patch electrode to the cell membrane and current clamping with zero current (Fig. 1D). To identify the recorded cell for two-photon imaging, and to verify that the membrane was not ruptured, electrodes were filled with ACSF containing Alexa Fluor 594.

Imaging in culture. All imaging was performed in a microscope stagemounted miniature incubator (Fig. 1B; TC-MIS-30; Bioscience Tools) set to $37^{\circ} \mathrm{C}$, and equipped with a humidified, sterilely filtered, $\mathrm{CO}_{2}$ controller set to $5 \%\left(\mathrm{CO}_{2}-\mathrm{MI}, \mathrm{CO}_{2}-500 \mathrm{ML}\right.$; Bioscience Tools). Slices were imaged through the coverslip glass-bottomed Petri dish using an objective inverter (LSM Tech) to effectively use an upright two-photon microscope as an inverted microscope. To maintain sterility, the Petri dishes remained covered throughout the imaging sessions and were handled with sterile gloves. A mark was placed on the dish to ensure that the slice was oriented in the same direction on consecutive days. The objective was positioned at a depth of $50 \mu \mathrm{m}$ up from the bottom (membrane side) of the slice. The same region of the CA1 pyramidal cell layer was imaged over several days by manually positioning the slice such that the angle of stratum pyramidale and (when possible) any landmarks (e.g., blood vessels) matched those in the image acquired on the previous day (Fig. 1E).

Two-photon images were acquired using custom-designed software and the scan head from a Radiance 2000MP (Bio-Rad), equipped with a $20 \times 0.95$ NA water-immersion objective (Olympus), and photomultiplier tubes with appropriate filters for YFP $(545 / 30)$ and CFP (450/80). A Spectra-Physics Mai Tai laser (Newport), set to $860 \mathrm{~nm}$, was used for two-photon excitation. All images of calcium dynamics were acquired using targeted path scanning (TPS; Lillis et al., 2008). Astrocytes were excluded from analysis based on three characteristics. (1) Patterns of activity show that cells with suprathreshold events that had a $>2 \mathrm{~s}$ and $10-90 \%$ rise time were excluded (Fig. 1E; Dani et al., 1992). (2) Morphology describes astrocytes with a "spongiform" appearance with highly ramified processes (Bushong et al., 2004). (3) Spatial distribution demonstrates that astrocytic soma tended to be primarily located outside the stratum pyramidale (Fig. $1 F$ ). To compute "calcium" traces, YFP and CFP signals were first low-pass filtered at $5 \mathrm{~Hz}$. Next, a first-order polynomial was fit to the YFP/CFP ratio, using least-squares minimization and was subtracted from the YFP/CFP ratio to correct for the different rates of bleaching in YFP and CFP.

Statistics. All $p$ values given were calculated using Pearson's correlation coefficient to test for significant changes in measured parameters over time. All values are presented as mean $\pm \mathrm{SE}$ in text and figures.

Epileptiform event detection. Epileptiform events were identified using the mean, baseline-subtracted YFP/CFP ratio: mean $\Delta R$. Peaks in mean $\Delta R$ represent large amplitude and/or highly synchronous activity in the recorded cells and approximately match a field potential recording (Lillis et al., 2012). Excursions in mean $\Delta R$ exceeding 0.15 were deemed epileptiform events. The event peak was determined by finding the maximum of mean $\Delta R$ between the initial threshold crossing and ending after $5 \mathrm{~s}$ or when mean $\Delta R$ drops below 0.15 , whichever came first. Criteria for distinguishing interictal spikes from seizures in animal models of epilepsy are only recently beginning to be developed (Fisher et al., 2014) and often cannot be described by a single parameter. In the data presented here, there were two distinct types of events: brief calcium (mean $\Delta R$ ) transients separated by $>1 \mathrm{~s}$ and tonic clonic-like seizures in which calcium remained elevated for several seconds, then resolved with synchronous bursting (Figs. 3-5). These events were well separated using duration alone: those lasting longer than $10 \mathrm{~s}$ were categorized as seizure-like events, while all other events were interictal epileptiform discharges. Although these are not clinical seizures as the terms imply, for the sake of being succinct we henceforth refer to these events as "seizures" and "interictal bursts." For the purposes of characterizing interictal burst and seizure onset dynamics, individual cellular threshold crossings (threshold: $\Delta r=0.2$; Fig. $1 D$ ) were used to calculate an onset time for each cell relative to the interictal burst/seizure peak. 
A

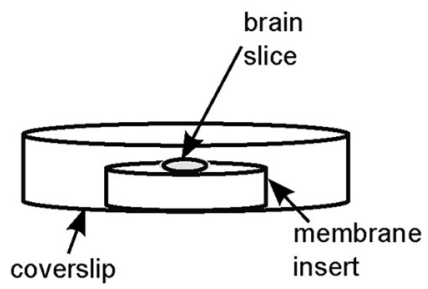

C

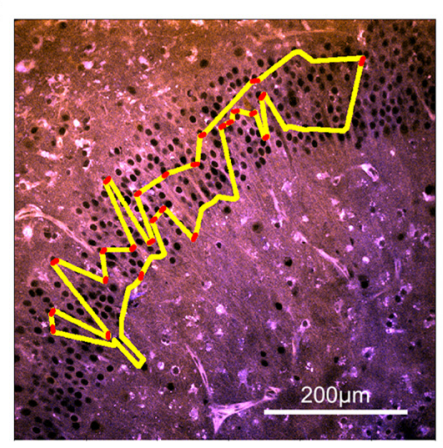

E

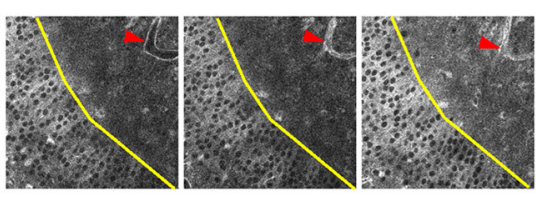

F

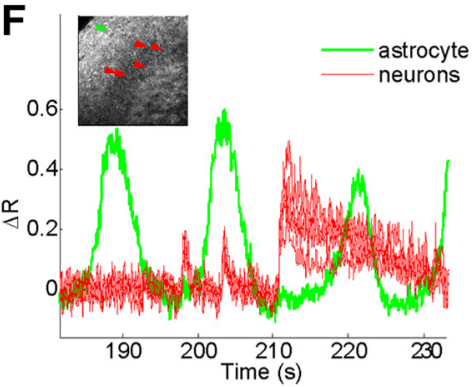

G

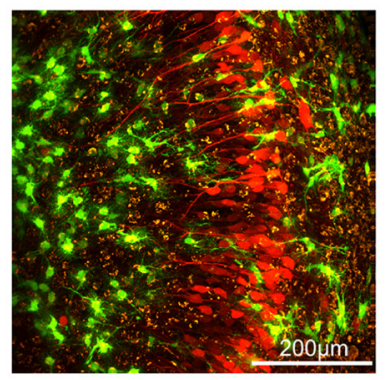

B

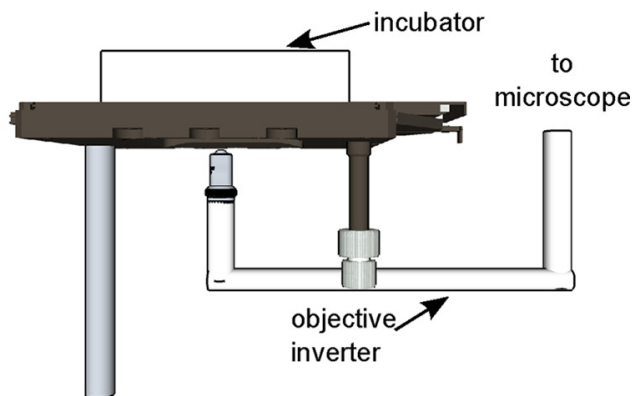

D1

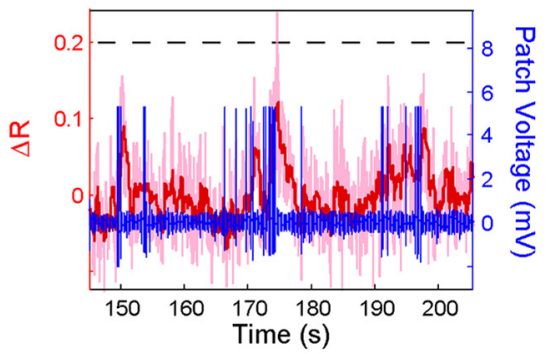

D2

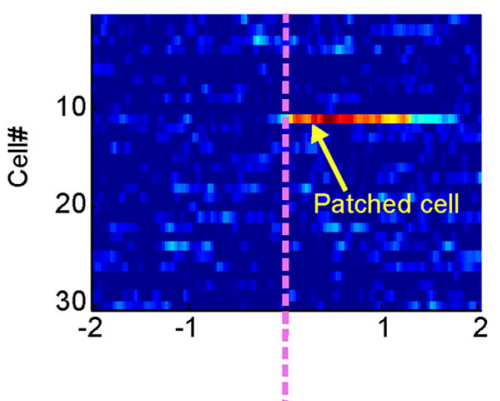

D3

$\frac{x}{4}$

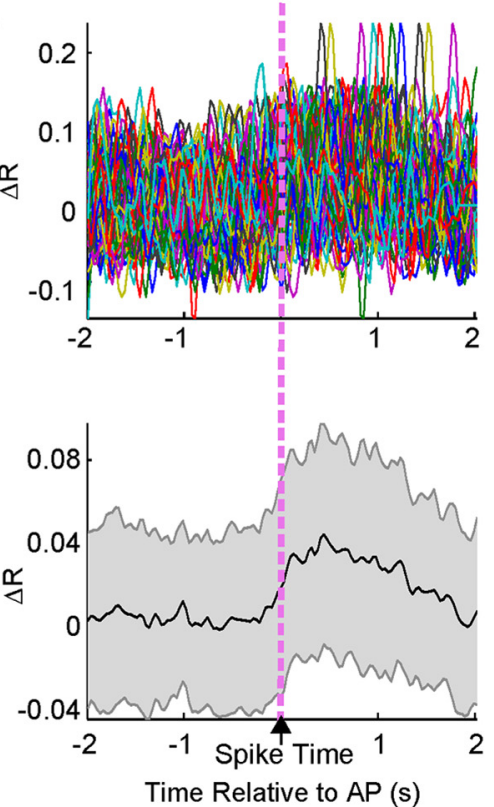

Figure 1. Imaging epileptogenesis. $\boldsymbol{A}, \boldsymbol{B}$, To image physiological changes associated with the emergence of an epileptic network, slices were grown in an optically accessible environment and imaged in a sterile, humidified, $\mathrm{CO}_{2}$-controlled stage-mounted incubator. $C$, Slices were made from animals expressing calcium indicator YC3.6 in all brain cells and the CA1 pyramidal cell layer was imaged using two-photon targeted path scanning. D, Simultaneous calcium imaging and loose-patch electrophysiological recordings determined that we could fluorometrically detect single action potentials with significant spike-triggered averaging (D2), but could not significantly differentiate them from baseline on a single trial basis (D3, D4). Small bursts of action potentials, corresponding to a change in YFP/CFP ratio of 0.2 , were distinguishable from baseline. The light pink trace in $\mathbf{D 1}$ was low-pass filtered at $5 \mathrm{~Hz}$, as were all analyzed calcium signals. The dark red trace was low-pass filtered at $1 \mathrm{~Hz}$ and is shown for reference only. $\boldsymbol{E}$, The orientation of the pyramidal cell layer (yellow curve) and notable features such as blood vessels (red arrowheads) were used as fiducial markers in returning to the same subregion of CA1 on consecutive days. $\boldsymbol{F}, \mathbf{G}$, Astrocytes were readily distinguishable from neurons based on both calcium dynamics and spatial distribution. 
Network analysis. Zero-lag correlation was used as a measure of functional connectivity in the network analyses presented here. For all crosscorrelation computations, data were first standardized by subtracting the mean and dividing by the SD. Correlation coefficients were computed between all pairs standardized calcium traces. To determine significance, correlation analyses were performed on 200 sets of randomized surrogate calcium traces with amplitude spectra matching the recorded data. Surrogate time series were generated using the iterative amplitude adjusted Fourier transform algorithm (Schreiber and Schmitz, 1996). For each pair of neurons, a distribution of correlation strengths was computed using the 200 pairs of surrogate traces and the 99 th percentile was chosen as a threshold for significance.

The MatlabBGL package (Gleich, 2009) was used to compute the graph analytical statistics mean path length and betweenness centrality (graphically defined in Fig. 7). For these analyses, each neuron was treated as a node on the graph. Mean path length was computed using the inverse of correlation strength as the "distance" between two nodes. Betweenness centrality was computed as the average fraction of shortest paths on which a given node falls (i.e., the degree to which a neuron acts as a "hub" between other neurons; Freeman, 1977). Windowed statistics were calculated using a 500 sample sliding window, shifted in 50 sample steps, corresponding to $\sim 13 \mathrm{~s}$ windows with a $1.3 \mathrm{~s}$ step size. Sample period is inherently recording specific with TPS recordings, but did not significantly change with time in culture $(p=0.24)$. Thus, seizuretriggered correlation averages were computed across slices using correlation windows as a time base and time axes for Figure 7 are approximate.

\section{Results}

The natural history of epileptogenesis in hippocampal organotypic slice cultures has been characterized using both acutely sampled and chronic field potential recordings (DyhrfjeldJohnsen et al., 2010; Berdichevsky et al., 2012). Here we describe changes in the spatial organization of epileptiform activity in the CA1 pyramidal cell layer as interictal bursts and seizures emerge.

We first conducted electrophysiological recordings to test whether epilepsy evolves in this preparation as a consequence of alterations in intrinsic neuronal properties or imbalances in the rate of excitatory versus inhibitory synaptogenesis. Dual wholecell patch-clamp recordings of spontaneous and miniature postsynaptic currents were made from CA1 pyramidal neurons at 1, 5, and 8 DIV. mPSCs were recorded during the blockade of spiking activity and represent the underlying network structure, while sPSCs are driven by action potential-dependent synaptic activity and are thus a measure of spontaneous network dynamics (which presumably, at least partially result from network structure). Any epileptiform discharges present during recording of sPSCs were excluded from analysis.

Electrophysiological properties measured are summarized in Table 1. Briefly, the frequency of recorded excitatory and inhibitory spontaneous (Fig. $2 C$; sEPSC: $p=2.4 \times 10^{-35}, n=193$ cells; sIPSC: $p=1.95 \times 10^{-14}, n=153$ cells) and miniature (Fig. $2 D$; mEPSC: $p=0.0015, n=78$ cells; mIPSC: $p=1.05 \times 10^{-5}$, $n=81$ ) postsynaptic currents increased over the first $8 \mathrm{DIV}$. The sEPSC/sIPSC amplitude ratio did not significantly change (DIV 1, $0.96 \pm 0.06$; DIV 5, $1.00 \pm 0.11$; DIV 8, $1.14 \pm 0.06 ; p=0.154$; $n=137$ ), while the sEPSC/sIPSC frequency ratio increased (DIV $1,0.87 \pm 0.14 ;$ DIV 5, $1.19 \pm 0.09 ;$ DIV 8, $1.84 \pm 0.16 ; p=1.35 \times$ $\left.10^{-6} ; n=137\right)$, reflecting changes in network activity. However, neither the mEPSC/mIPSC amplitude ratio (DIV 1, $0.64 \pm 0.06$; DIV 5, $1.47 \pm 0.17 ;$ DIV 8, $1.03 \pm 0.09 ; p=0.3617 ; n=59$ cells) nor the mEPSC/mIPSC frequency ratio (DIV 1, $0.31 \pm 0.08$; DIV $5,0.89 \pm 0.34 ;$ DIV 8, $0.62 \pm 0.33 ; p=0.2848 ; n=59$ cells $)$ significantly changed over time. The resting membrane potential also did not change with time in culture (DIV 1, $69.7 \pm 4.4 \mathrm{mV}$;
Table 1. Summary of electrophysiological changes during epileptogenesis

\begin{tabular}{|c|c|c|c|c|c|}
\hline & $\begin{array}{l}\text { DIV } 1 \\
\text { Mean } \pm \text { STD }\end{array}$ & $\begin{array}{l}\text { DIV } 5 \\
\text { Mean } \pm \text { STD }\end{array}$ & $\begin{array}{l}\text { DIV } 8 \\
\text { Mean } \pm \text { STD }\end{array}$ & Units & Significant \\
\hline sEPSC frequency & $1.13 \pm 0.60$ & $3.81 \pm 2.03$ & $8.74 \pm 4.13$ & $\mathrm{~Hz}$ & + \\
\hline sIPSC frequency & $1.91 \pm 1.04$ & $3.86 \pm 1.76$ & $5.23 \pm 2.40$ & $\mathrm{~Hz}$ & + \\
\hline mEPSC frequency & $0.83 \pm 0.57$ & $2.26 \pm 1.69$ & $3.29 \pm 2.49$ & $\mathrm{~Hz}$ & + \\
\hline mIPSC frequency & $1.69 \pm 1.47$ & $2.58 \pm 1.38$ & $4.31 \pm 2.30$ & $\mathrm{~Hz}$ & + \\
\hline $\begin{array}{l}\text { SEPSC/SIPSC amplitude } \\
\text { ratio }\end{array}$ & $0.96 \pm 0.38$ & $1.00 \pm 0.76$ & $1.14 \pm 0.42$ & & - \\
\hline $\begin{array}{l}\text { sEPSC/sIPSC frequency } \\
\text { ratio }\end{array}$ & $0.87 \pm 0.90$ & $1.19 \pm 0.65$ & $1.84 \pm 1.04$ & & + \\
\hline $\begin{array}{l}\mathrm{mEPSC} / \mathrm{mIPSC} \text { amplitude } \\
\text { ratio }\end{array}$ & $0.64 \pm 0.19$ & $1.47 \pm 0.85$ & $1.03 \pm 0.43$ & & - \\
\hline $\begin{array}{l}\mathrm{mEPSC} / \mathrm{mIPSC} \text { frequency } \\
\text { ratio }\end{array}$ & $0.31 \pm 0.27$ & $0.89 \pm 1.75$ & $0.62 \pm 1.58$ & & - \\
\hline $\begin{array}{l}\text { Resting membrane } \\
\text { potential }\end{array}$ & $69.7 \pm 4.4$ & $71.1 \pm 5.3$ & $69.8 \pm 4.3$ & $\mathrm{mV}$ & - \\
\hline Input resistance & $205 \pm 71$ & $159 \pm 52$ & $148 \pm 43$ & $\mathrm{M} \Omega$ & + \\
\hline
\end{tabular}

Pairs of neurons were recorded from using dual whole-cell patch clamp at 1,5, and 8 DIV. As detailed in the Results section, spontaneous and miniature and excitatory and inhibitor postsynaptic currents all increased in frequency, whereas the balance of excitation and inhibition did not change, except in the case of spontaneous PSC frequency. The changes in resting membrane potential and input resistance were consistent with normal development and extensive synaptogenesis. (+ significance indicates $p<0.05$ )

DIV 5, $71.1 \pm 5.3 \mathrm{mV}$; DIV 8, $69.8 \pm 4.3 \mathrm{mV} ; p=0.75, n=147$ cells). However, the input resistance significantly dropped (from DIV 1, $205 \pm 71 \mathrm{M} \Omega$ to DIV 5, $159 \pm 52 \mathrm{M} \Omega$ and DIV 8, $148 \pm 43 \mathrm{M} \Omega ; p=1.3 \times 10^{-5}, n=148$ cells). Together, these electrophysiological results are consistent with extensive synaptogenesis and axonal outgrowth seen during normal development (Gomez-Di Cesare et al., 1997; Tyzio et al., 2003), but steady-state membrane properties were not commensurate with changes in intrinsic excitability and miniature postsynaptic currents did not reflect an imbalance of inhibitory versus excitatory synaptogenesis.

Epilepsy could also develop as a consequence of excessive recurrent synaptic connectivity. To begin to assess this, we measured the degree of correlation of synaptic activity in paired whole-cell recordings. The cross-correlation of spontaneous and miniature EPSCs between the two recorded neurons was computed for epochs of time containing no epileptiform activity. There was a steady increase in $\operatorname{sEPSC}\left(p=1.54 \times 10^{-7}, n=78\right.$ pairs) and sIPSC ( $p=9.46 \times 10^{-6}, n=56$ pairs $)$ correlation (Fig. $2 A, E$ ), while the mEPSC correlation did not significantly change ( $p=0.15, n=23$ pairs) and mIPSC correlation increased slightly (Fig. $2 B, F ; p=0.0017, n=29$ pairs).

\section{Imaging network changes in epileptogenesis}

To track network correlation changes on a larger scale, we developed a method for sequential sterile imaging of cellular calcium dynamics in hippocampal organotypic slice cultures prepared from mice expressing the genetically encoded calcium indicator Yellow Cameleon 3.6 (YC3.6) in Nestin-expressing cells (Fig. 1A$C)$. Two-photon TPS imaging (Lillis et al., 2008) was used to image YC3.6-expressing cells in CA1 stratum pyramidale. Cellattached patch recordings revealed that single action potentials could be fluorometrically detected with spike-triggered averaging (Fig. 1D2), but could not be reliably distinguished from noise on a single trial basis (Fig. 1D3,D4). Brief bursts of action potentials resulted in a change in the YFP/CFP ratio of $>0.2$ that was discernible in single trials (Fig. $1 D 1$, light pink trace; $t=173$ ). This threshold, $\Delta r=0.2$, was used for displaying raster plot data in Figures 3-5, computing the relative amount of nonictal activity (Fig. 4D), and computing "cell onset times" (Figs. 4, 5), but cor- 
A

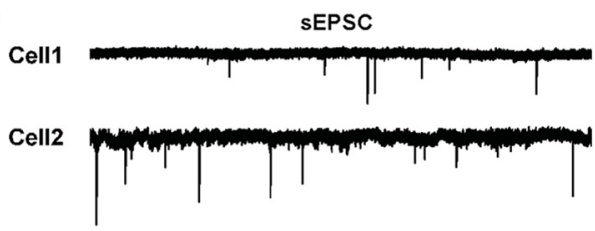

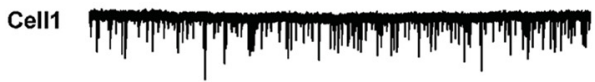

Cell2

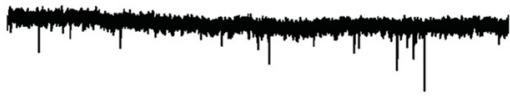

Cell1

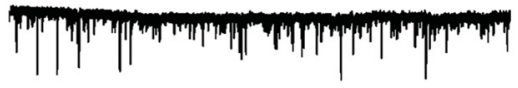

Cell2

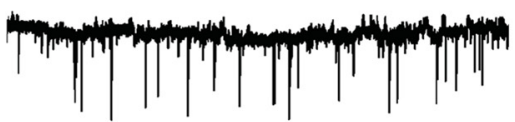

C

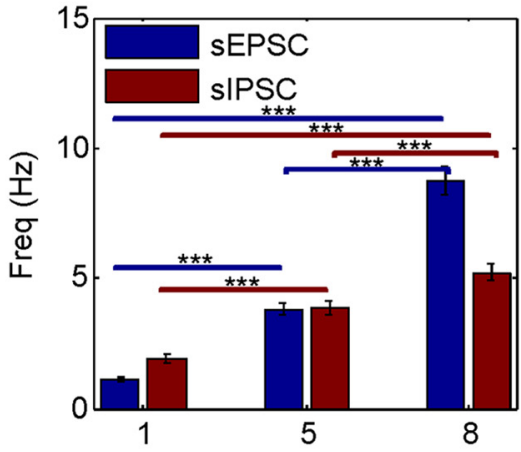

E

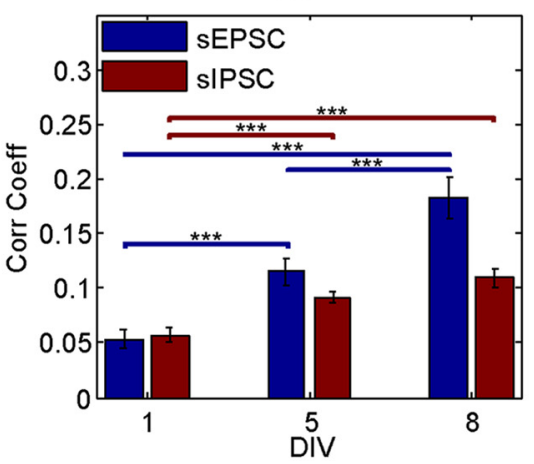

B

DIV 1
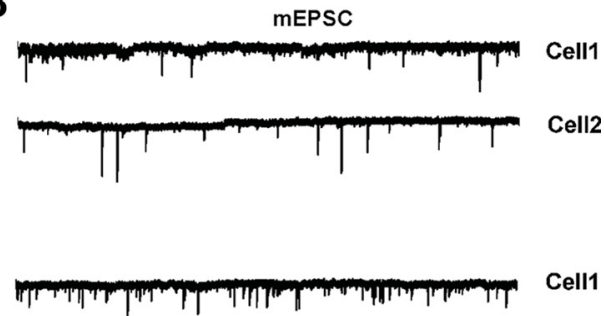

DIV 5

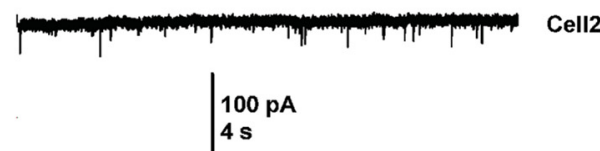

DIV 8

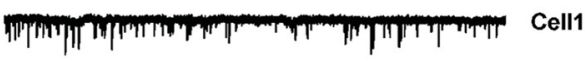

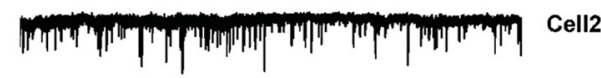

D

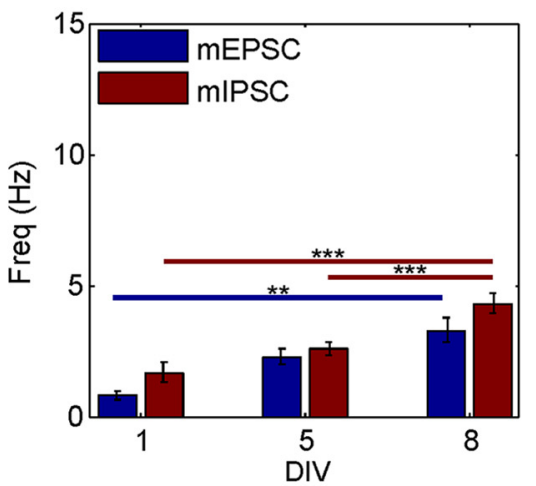

F

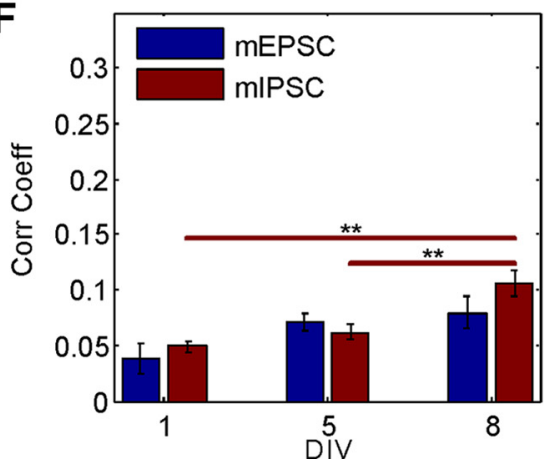

Figure 2. Dual whole-cell patch recordings. $A, B$, Pairs of CA1 pyramidal neurons were recorded in voltage clamp to measure both spontaneous (excluding epileptiform discharges) and miniature synaptic currents. $\boldsymbol{C}, \boldsymbol{D}$, Spontaneous and miniature excitatory and IPSC frequency increased throughout the first 8 DIV. $E$, The correlation strength of (nonictal) spontaneous excitatory and inhibitory activity significantly increased as epileptogenesis progressed. $\boldsymbol{F}$, The trend toward increased mEPSC correlation did not reach significance, but mIPSC correlation slightly increased by DIV 8 . ${ }^{* *} p<$ $\left.0.01,{ }^{* * *} p<0.001\right)$.

relation analyses were performed on unthresholded data. As described below, we first imaged with hourly resolution the advent and progression of interictal bursting (Fig. 3). Next we characterized, with daily recordings and correlation analysis, the development of seizures and the evolution of seizure onset dynamics (Figs. 4-7).

\section{Interictal activity}

To examine the earliest emergence of synchronous activity, three slices were imaged hourly for the first $24 \mathrm{~h}$ in vitro $(n=3$ slices, 72 recordings, 4912 detected bursts). The first signs of correlated firing appeared 2-3 $\mathrm{h}$ after slicing, when subsets of the imaged cells began to exhibit weakly correlated bouts of activity (Fig. 3A), which were termed interictal bursts. Interictal burst peak times were calculated using the mean, baseline-subtracted YFP/CFP fluorescence ratios, computed across all recorded neurons (Fig. 3, left column, mean $\Delta R$ ). Individual cellular calcium threshold crossings (threshold: YFP/CFP $\Delta r=0.2$; Fig. $1 D$ ) were used to calculate an onset time for each cell relative to the burst peak. The increasing slope and rightward shift in the cumulative distribution of onset times suggests that bursts become more synchronous over the first $24 \mathrm{~h}$ in culture (more rapid onsets in Fig. $3 \mathrm{~A}$, right column, $B ; p=2.4 \times 10^{-29} ; n=3$ slices, 72 recordings, 4912 detected bursts). 
A
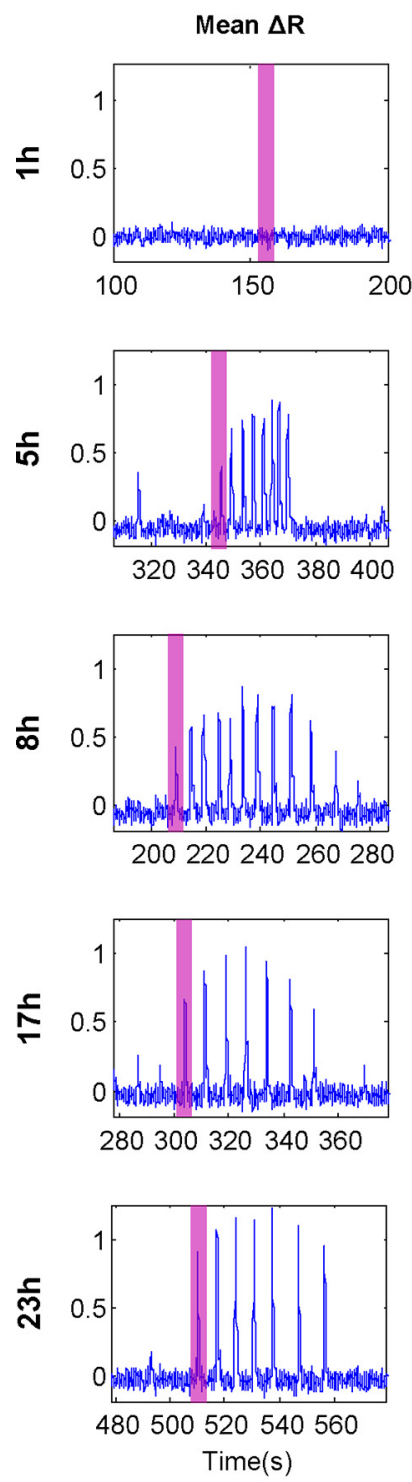
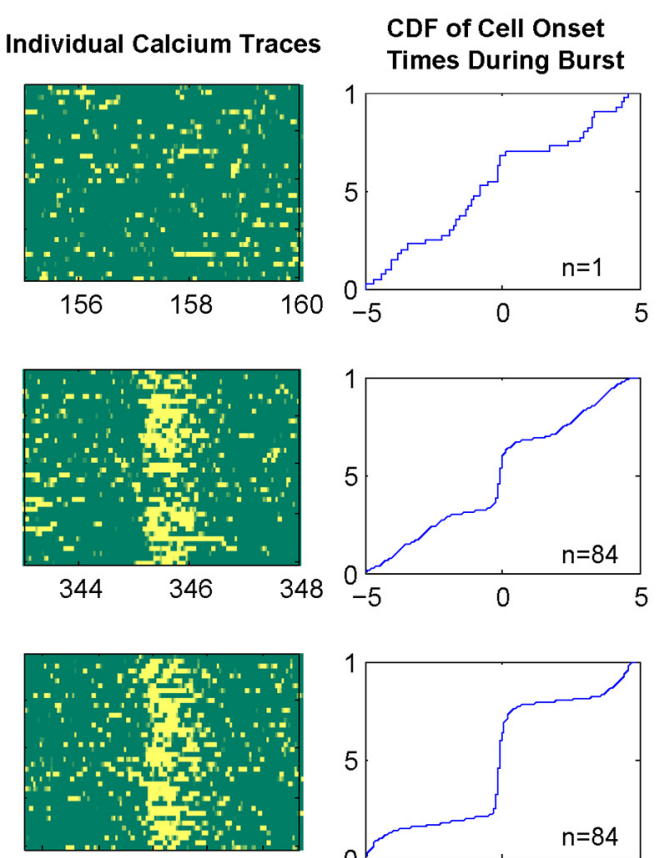

207208209210211
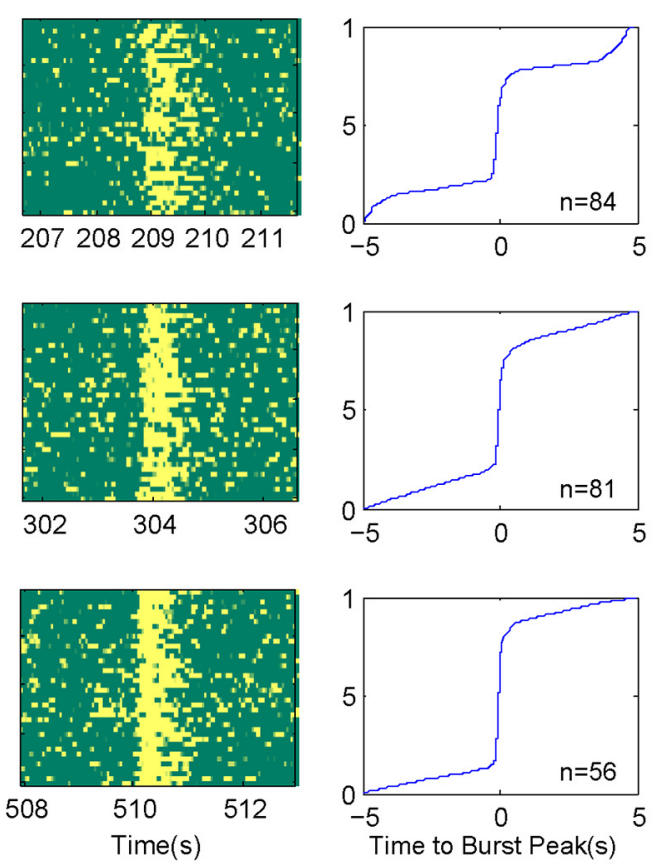
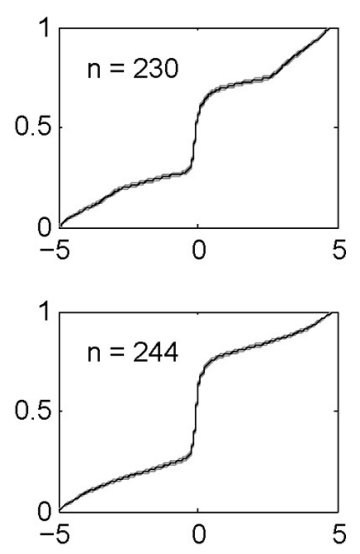

CDF of Cell Onset

Times During Burst

All slices
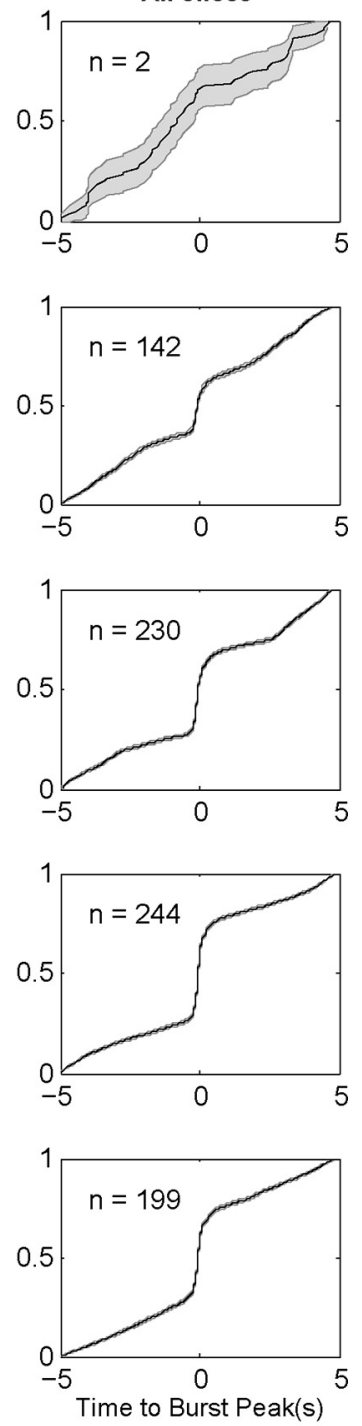

B

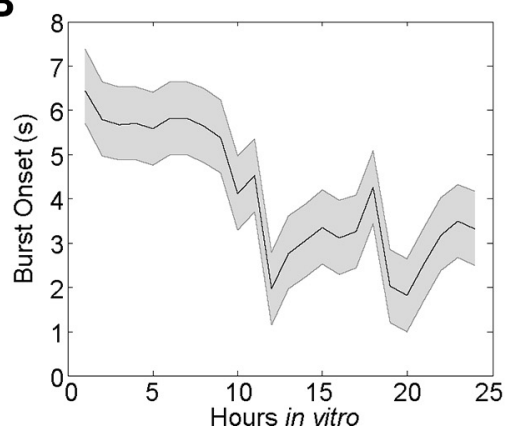

Figure 3. Imaging the emergence of interictal bursts. To examine the earliest emergence of synchronous activity, three slices were imaged hourly for the first $24 \mathrm{~h}$ in vitro ( $n=3$ slices, 72 recordings, 4912 detected bursts). $\boldsymbol{A}$, Raster plots for interictal bursts highlighted in pink box are shown in the second column. The first signs of correlated firing appeared $2-3 \mathrm{~h}$ after slicing, when subsets of the imaged cells began to exhibit weakly correlated activity (top two rows, left two columns). By the end of the DIV 1, cells were recruited more efficiently into the population burst (bottom two rows, left two columns). This apparent buildup of activity was quantified by computing cell onset times relative to interictal burst peak. Burst peak times were calculated using the mean calcium trace, while individual cellular calcium threshold crossings (threshold:YFP/CFP $\Delta R=0.2$ ) were used to calculate an onset time for each cell relative to the burst peak. The increasing slopes and rightward shifts in the cumulative distribution of onset times (third and fourth columns) demonstrate that population bursts became more rapid and synchronous. $\boldsymbol{B}$, Burst onset time, defined as 80th to 20th percentile of CDFs, steadily decreased.

\section{Ictal activity}

To study the emergence and evolution of seizures, daily recordings were made during the first week in vitro from 30 cells in CA1 stratum pyramidale $(n=5$ slices, 40 recordings, 113 detected seizures). Tonic clonic-like seizures were apparent in the recorded calcium traces as early as 1 DIV (Fig. $4 A, B$ ). We quantified changes in "functional connectivity" of the network by computing the crosscorrelation between calcium traces for all pairs of neurons. Plots of 
A

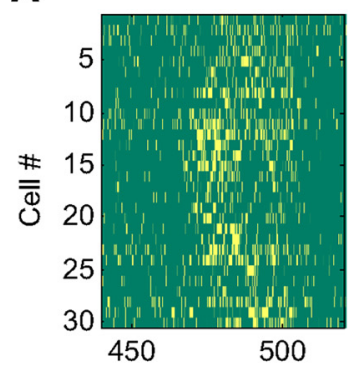

B

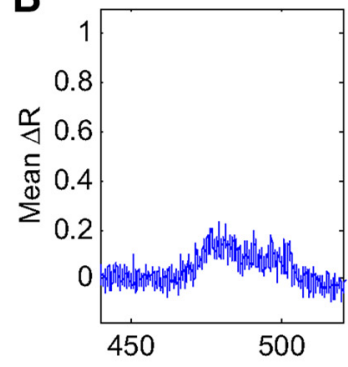

C

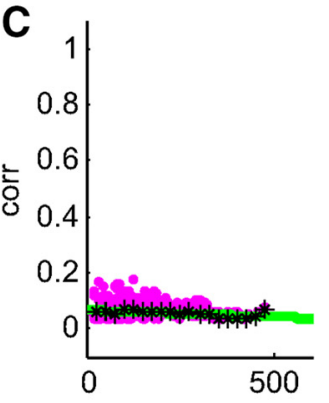

DIV1

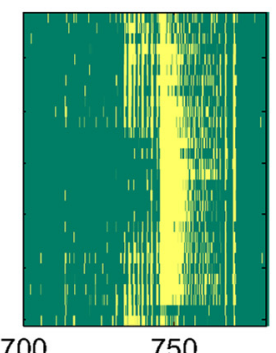

750
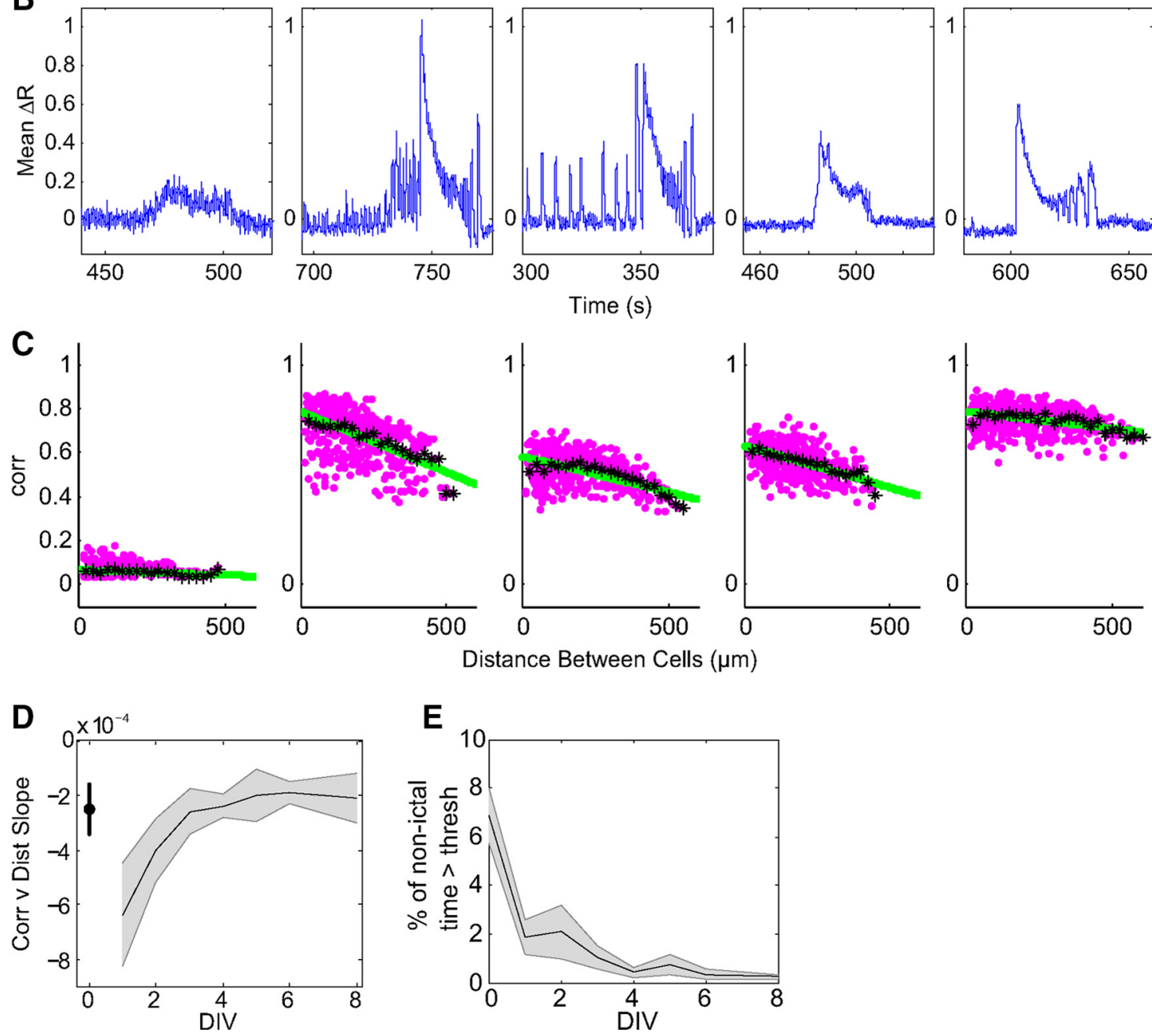

Figure 4. Evolution of ictal activity. Representative recordings from different phases of epileptogenesis are shown as raster plots of the $30 \mathrm{imaged}$ cells $(\boldsymbol{A})$ and mean change in YFP/CFP ratio ( $\boldsymbol{B}$; i.e., mean of 30 cells shown in $\boldsymbol{A}$ ). Tonic clonic-like seizure activity was apparent as early as 1 DIV. There was substantial uncorrelated activity between seizures on DIV 0 - 4. After DIV 4, dynamics more closely resembled status epilepticus, with essentially no "baseline activity" between postictal depression and the subsequent seizures. $\boldsymbol{C}$, To examine the spatial dependence of functional connectivity, correlation (corr) strength for each pair of calcium traces (pink dots) was plotted as a function of the physical distance between the cells. Pairwise correlations (pink dots) were averaged in $50 \mu \mathrm{m}$ bins (black stars) and fit with a line (solid green). Early in epileptogenesis, the strongest correlations were predominantly local. At later DIV, correlation strength was uniformly high and nearly independent of distance between cells. $\boldsymbol{D}$, The slope of the correlation versus distance plots shown in Capproached zero as epileptogenesis progresses. $\boldsymbol{E}$, The fraction of time during which there was detectable neural activity decreased over the first 8 DIV, corresponding to reduced neuronal activity between seizures.

correlation coefficient versus physical distance between cells reveal predominantly local high correlations early in epileptogenesis (negative slope of correlation vs distance lines; Fig. 4C). On later DIV, correlation coefficients were more uniformly high, nearly independent of distance, as evidenced by the correlation versus distance slope approaching zero (Fig. 4C,D).

Raster plots of all 30 calcium traces (Figs. $4 A, 5 A$ ) reveal both synchronous activation and uncorrelated activity between seizures on 0-4 DIV. After 4 DIV, dynamics more closely resembled status epilepticus, with essentially no "baseline activity" between postictal depression and the subsequent seizures. This decrease in detectable $(\Delta R>0.2)$ interictal activity (Fig. $4 E ; p=5.8531 \times 10^{-6} ; n=5$ slices, 40 recordings, 113 detected seizures) contributed to the increase in correlation shown in Figure 4, $C$ and $D$, because at later dates the correlation reflected a larger fraction of highly synchronous ictal activity versus less synchronous interictal activity. 
A
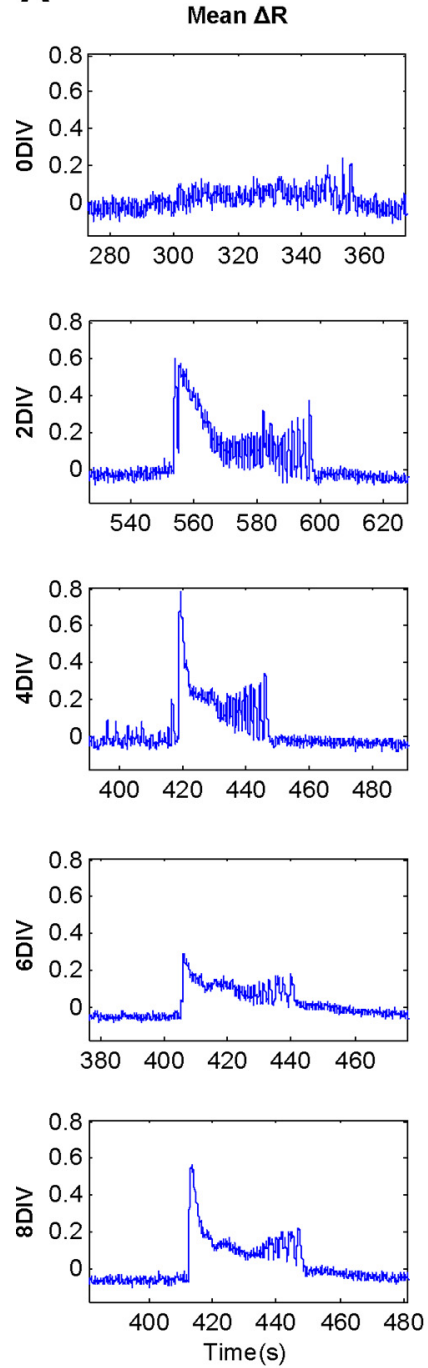

B

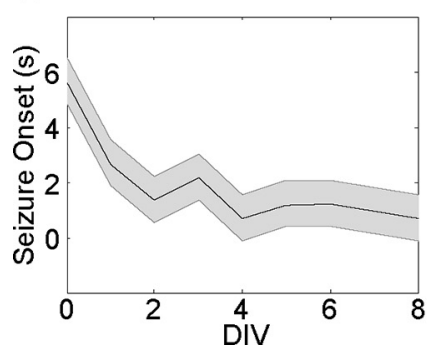

Individual Calcium Traces
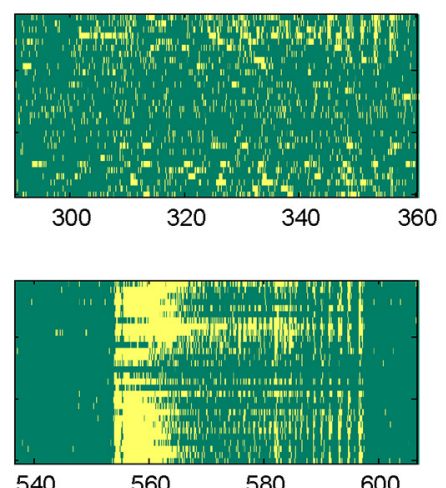

600
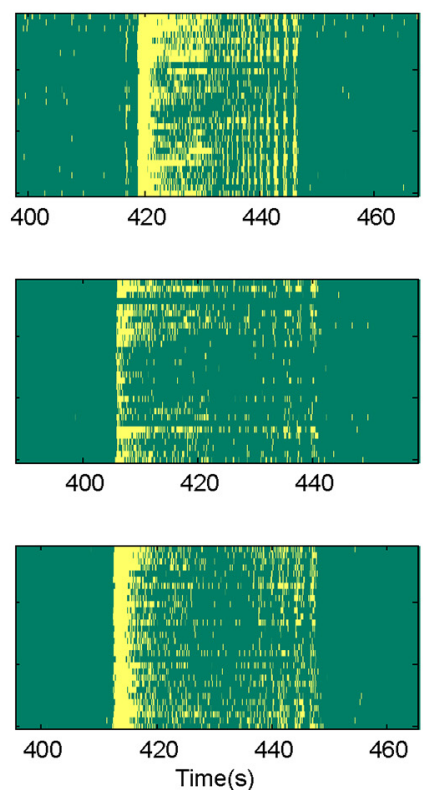

Cumulative Distribution
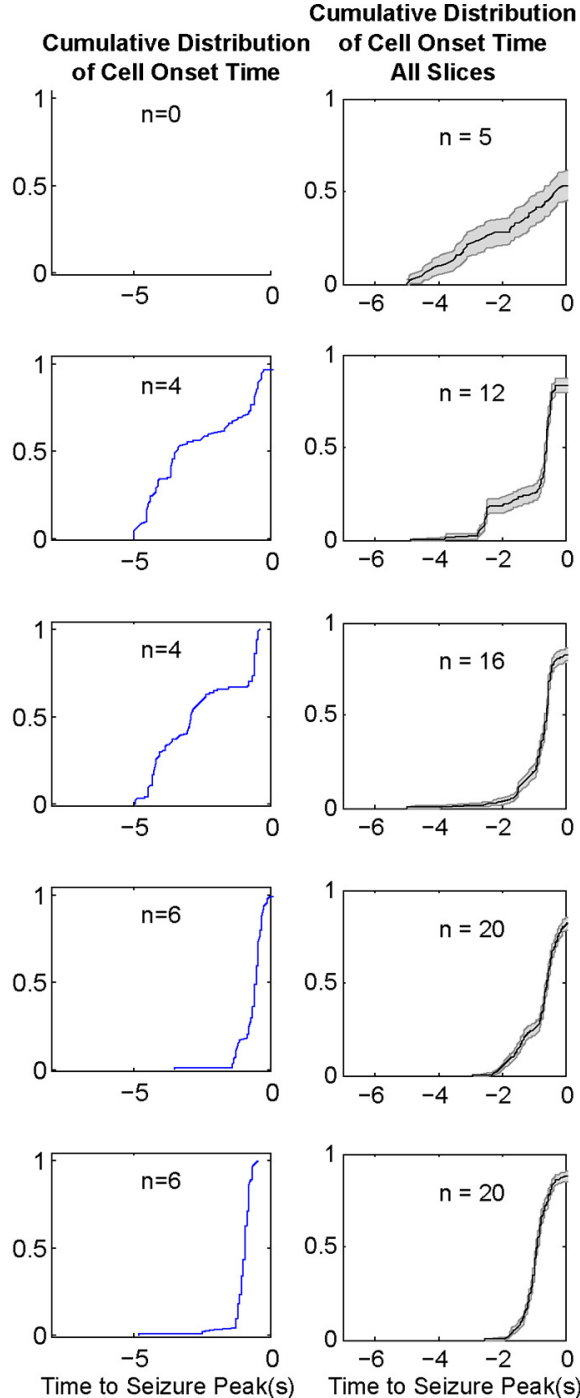

Figure 5. Seizure onset becomes more instantaneous. $A$, Mean $\Delta R$ (left column) and cellular calcium traces (second column) were used to quantify the rate at which neurons joined seizures. Seizure peak times were calculated as described for burst peaks in Figure 3. CDFs of the onset times of individual neurons relative to the seizure peak (third and fourth column) became steeper, indicating a more rapid and step-like seizure onset. $\boldsymbol{B}$, A plot of seizure onset time, defined as 80th to 20th percentile from the CDF data, reveals the trend that seizure onset became more instantaneous at later DIV.

In addition to the increased long-range correlation and decreased interictal activity, seizure onset became more instantaneous at later DIV. On early DIV, there was a gradual increase in pre-ictal activity (Figs. $4 A, B, 5 A$ ). This apparent buildup of activity was quantified, as with burst activation, by computing an onset time, relative to seizure peak, for each cell. Seizure peak times and cell onset times were calculated from the mean $\Delta R$ and individual neuronal calcium traces, respectively (Fig. $5 A$, left two columns). Cumulative distribution functions $(\mathrm{CDFs})$ of neuronal onset times relative to the sei- zure peak reveal that seizure onset became more rapid, synchronous, and step-like over the first $8 \mathrm{~d}$ in culture (Fig. 5A, right two columns). Seizure onset time, calculated as the time difference between the 80th and 20th percentiles of the $\mathrm{CDF}$, revealed a trend toward more rapid seizure onset as epileptogenesis progressed (Fig. $5 B ; p=1.03 \times 10^{-16} ; n=5$ slices, 40 recordings, 113 detected seizures). Notably, these changes did not drastically alter the tonic clonic-like structure of the seizures (Figs. 4,5$)$ or the mean seizure duration $(p=$ $0.3216)$ 
A

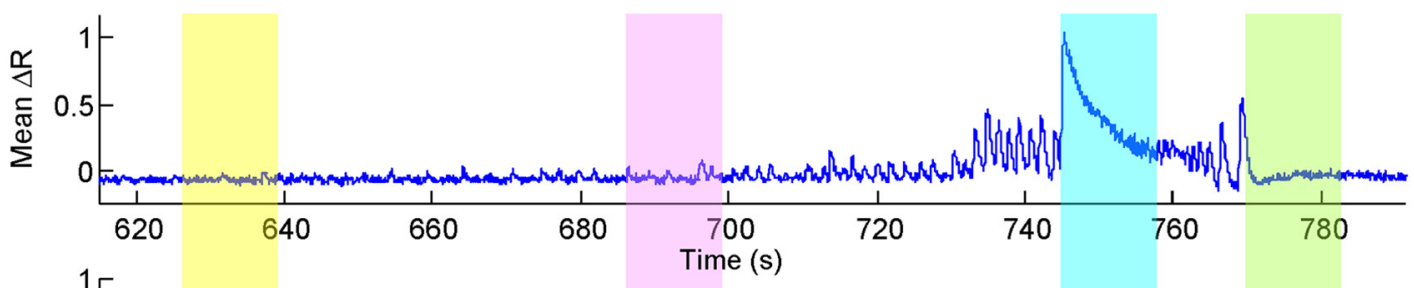

B

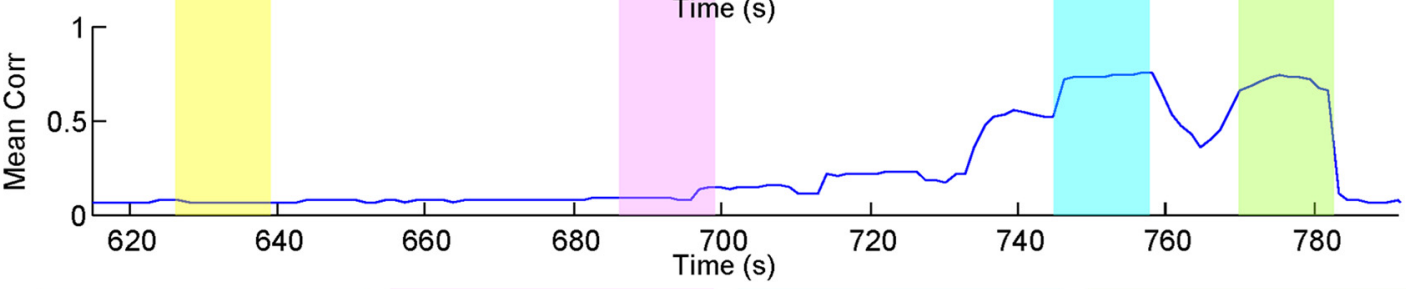

C
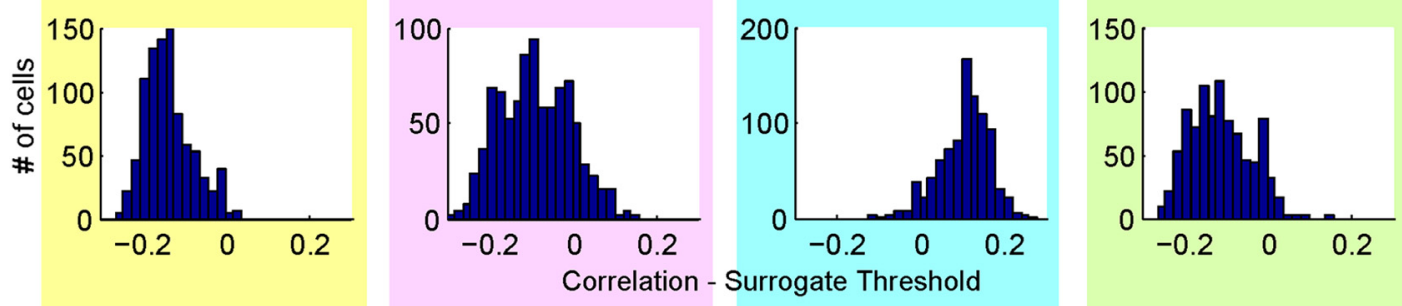

D
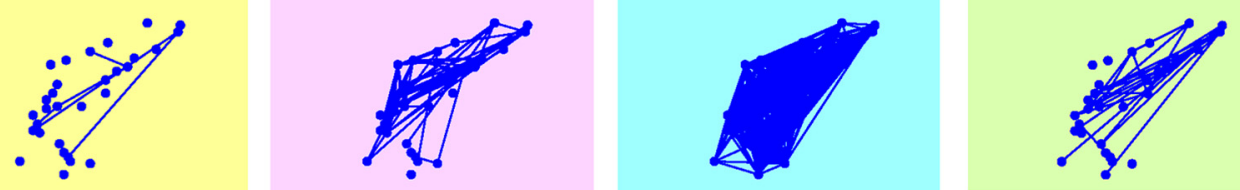

$\mathbf{E}$

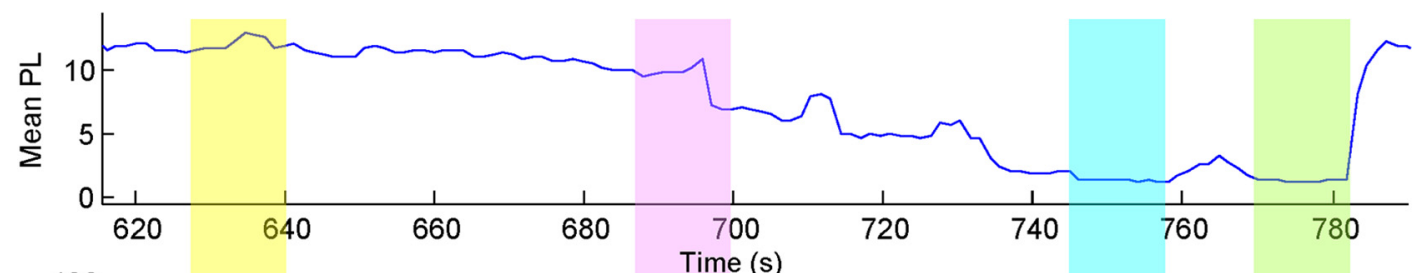

$\mathbf{F}$

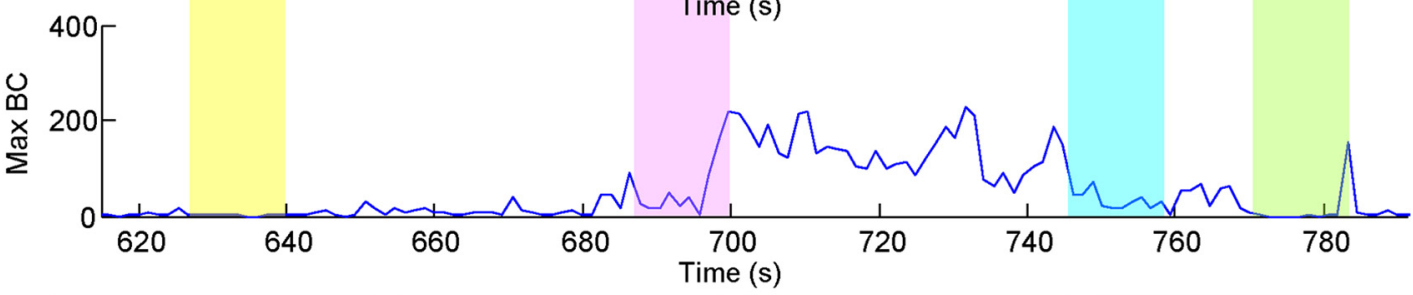

G
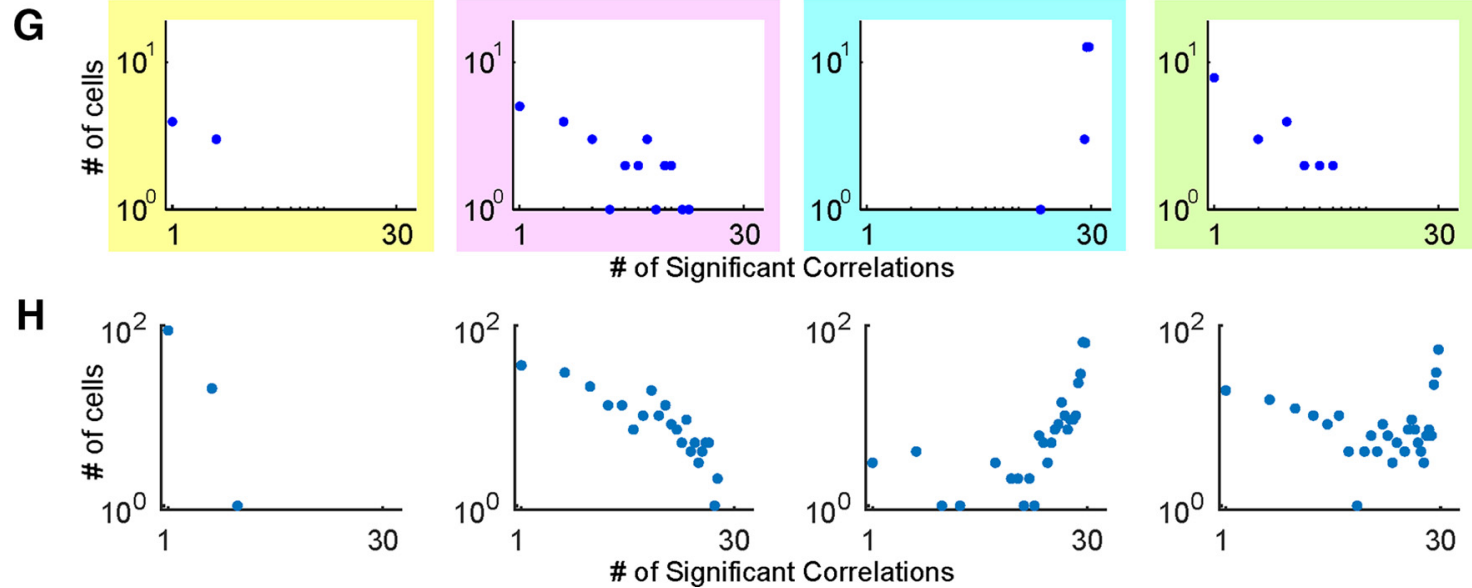

Figure 6. Dynamic changes in functional connectivity. Windowed correlation analyses were used to quantify changes in functional network connectivity that correspond to different modes of activity. $\boldsymbol{A}$, In early epileptogenesis (DIV 1), there is a slow pre-ictal buildup of neuronal calcium activity apparent in plots of mean $\Delta R$. $\boldsymbol{B}$, There is a corresponding increase in mean correlation. $\boldsymbol{C}$, Significant correlation (corr) thresholds were determined using phase-randomized surrogates. Histograms represent the distribution of cell pairs' correlation (Figure legend continues.) 


\section{Dynamic changes in functional connectivity}

In this study, we used the correlation between cellular calcium activities as a measure of functional network connectivity. Since functional network structure depends on the measured activity, it inherently changes with the dynamic state of the network (Feldt et al., 2010). We quantified these transitions in functional network state using a 500 sample windowed, zero-lag crosscorrelation between all pairs of neuronal calcium traces.

During the early phase of epileptogenesis, the gradual buildup of synchronous activity preceding seizure onset is reflected in the steady increase in mean correlation (Fig. 6A,B). Phase-randomized surrogates were generated for each pair of calcium segments and used (as described in Materials and Methods) to determine a threshold for significant correlations (Fig. $6 C)$. This information was used to generate graphs of network connectivity, wherein each node represents a neuron and vertices are drawn between significantly correlated pairs (Fig. 6D).

Mean path length and betweenness centrality are higher order measures of connectivity that were computed to quantify changes in functional network structure. Mean path length is calculated by finding the shortest path (where distance $=1$ /correlation coefficient) between all pairs of neurons (Fig. $7 B$ ). During the preictal increase in mean correlation, mean path length steadily dropped (Fig. 6E). Given its intimate connection to correlation (Newman, 2001; Opsahl et al., 2010), this finding is not unexpected. Betweenness centrality is calculated as the number of shortest paths on which each neuron falls (i.e., the extent to which each neuron acts as a "hub" in the network; Fig. 7C). Since the presence of strongly hub-like nodes is one of the defining characteristics of a small-world network, maximum betweenness centrality (MBC) represents an index of the extent to which the network can be described as having small-world structure (Fig. $6 F)$. When there was little synchronous activity in the network (Fig. 6, yellow box), connectivity was low, thus there were no hub-like neurons, and $\mathrm{MBC}$ was low. In the middle of a seizure, connectivity was essentially all to all; thus, the shortest path between two nodes was a direct connection (i.e., there were no opportunities for hubs between directly connected neurons) and MBC was low (Fig. 6, blue box). In the transition between quiescence and seizure, when there was sparse synchronous activity, MBC peaked and small-world network structure transiently emerged (Fig. 6, pink and green boxes).

Another way to test for small-world network structure is to plot the degree distribution (i.e., histogram of number of significant correlations per cell). A scale-free network, which is an "ultrasmall" world network (Cohen and Havlin, 2003), has a power law distribution. While the sampling size is relatively small in this study, the peaks in betweenness centrality correspond to a linear trend in log-log plots of degree distribution (Fig. 6G, pink

$\leftarrow$

(Figure legend continued.) minus the 99th percentile of phase-randomized surrogate correlation for each pair (values $>0$ represent significant correlations). $\boldsymbol{D}$, When correlation exceeded threshold, vertices were drawn between the pair of neurons (nodes) on the graph of "functional connectivity." $\boldsymbol{E}$, The mean path length (PL; where "distance" of a vertex $=1 /$ correlation) between all pairs of neurons steadily decreased during the pre-ictal buildup of activity. $\boldsymbol{F}$, Maximum betweenness centrality (BC), a measure of small-world network structure, peaked during the times corresponding to transitions to (pink) and from (green) seizure activity, at which time levels of functional connectivity were moderate, but remained low when functional connectivity was low (yellow) or uniform (blue). $\boldsymbol{G}, \boldsymbol{H}$, Log-log histograms of degree, the number significant correlations per cell, for the sample shown in $\boldsymbol{A}-\boldsymbol{F}(\boldsymbol{G})$ and for all samples $(\boldsymbol{H})$ reveal an approximately power law distribution during times of peak betweenness centrality, suggesting transient scale-free network topologies. and green boxes), supporting the idea that the network is transiently small world and perhaps also scale free. To characterize this transition across slices, seizures were analyzed from each slice on at least $2 \mathrm{~d}$ in which there was a pre-ictal buildup of activity (i.e., not an abrupt seizure onset). The connectivity patterns observed in the population data (Fig. $6 H$ ) mirror those observed in the illustrative example shown in Fig. 6G, suggesting that the state-dependent fluctuations in functional network architecture is not unique to the representative slice shown.

To quantify the evolution of functional network state transitions shown in Figure 6, seizure-triggered averages of correlation, mean path length, and betweenness centrality were computed with data from five slices followed over 8 DIV. During the first $3 \mathrm{~d}$ of seizures, there is a steady increase in correlation and decrease in mean path length (Fig. $7 A, B$ ). By 4 DIV there is a nearly step-like increase in correlation and decrease in mean path length at seizure onset. In early epileptogenesis, during the slow pre-ictal buildup of activity, maximum betweenness centrality peaked (Fig. 7C). Once seizures evolve into a more instantaneous onset, the network abruptly transitions from low connectivity to all-toall connectivity; thus, maximum betweenness centrality remained low (Fig. 7C).

\section{Discussion}

Serial calcium imaging of network activation during early epileptogenesis revealed a progressive increase in the rate of synchronization that continuously evolves from the earliest interictal clustering of activity through the development of the first seizures continuing through the development of electrographic status epilepticus. Dual whole-cell recordings demonstrated that this evolution is associated with increases in the rates of spontaneous and action-potential independent transmitter release, but not with proconvulsant alterations in membrane properties or with the balance of excitatory versus inhibitory synaptogenesis, as estimated from the rates of miniature synaptic currents. Electrophysiological and calcium imaging measures of interneuronal correlation increased throughout epileptogenesis, as did estimates of network connectivity based on these correlations. Thus we conclude that progressive enhancements of recurrent synaptic circuitry are the most likely substrate for epileptogenesis, although the pattern of this increased connectivity remains to be determined.

\section{What are the critical elements of epileptogenesis?}

Our prior studies indicate that in this model the glutamate receptor antagonist kynurenate blocked seizure activity (Berdichevsky et al., 2012), but on washout the slice immediately began to seize repeatedly at a rate fivefold higher than untreated controls, suggesting that synaptic reorganization proceeded in the absence of synaptic activity (consistent with studies of homeostatic synaptic plasticity; Turrigiano et al., 1998). Inhibition of the mTOR pathway, which is critical for synaptogenesis and long-term potentiation of existing synapses (Tang et al., 2002; Dwyer and Duman, 2013), is the only treatment demonstrated (thus far) to inhibit epileptogenesis in this model (Berdichevsky et al., 2013).

Both inhibitory and excitatory synaptic activity levels and the strength of network coupling progressively increased during epileptogenesis. Prior studies have demonstrated increases in recurrent glutamatergic synaptic activity from 1 to $3 \%$ in acute slices (Miles and Wong, 1986) to 33\% in the hippocampal organotypic slice preparation (Debanne et al., 1995; Pavlidis and Madison, 1999). Prolific and ectopic anatomical sprouting (Gutiérrez and Heinemann, 1999; De Simoni et al., 2003) and dendritic spine 
A

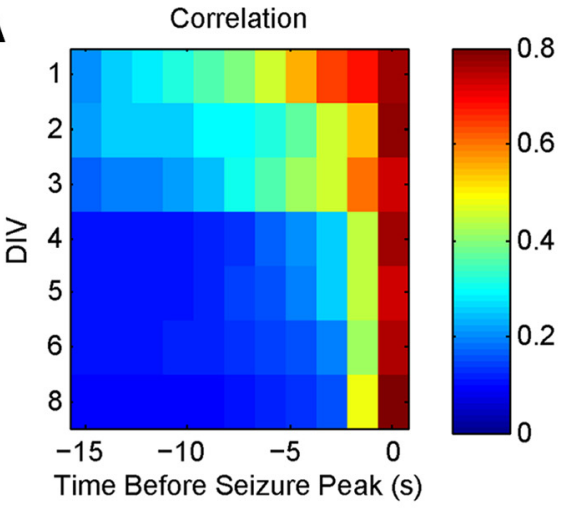

B

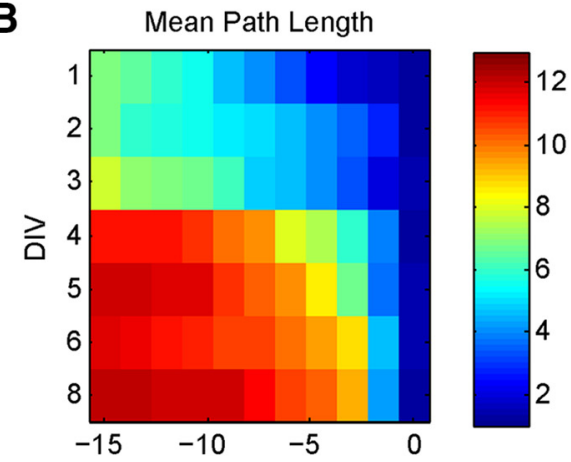

Time Before Seizure Peak (s)

C Max Between Centrality

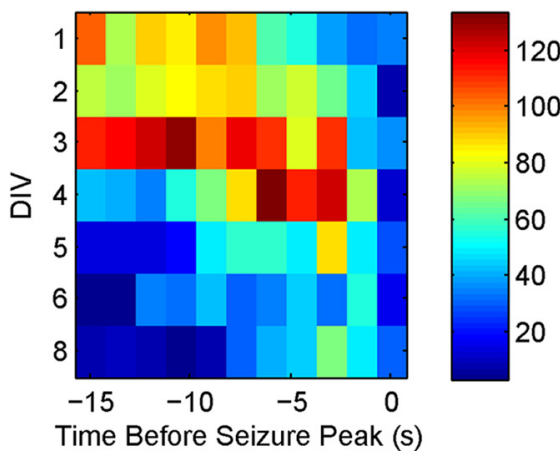

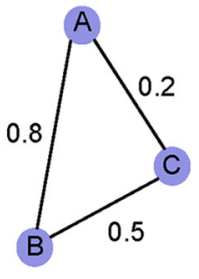

$$
\begin{aligned}
& \frac{A B+A C+B C}{3}= \\
& \frac{0.8+0.2+0.5}{3}=0.5
\end{aligned}
$$

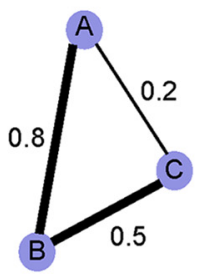

$P L_{A C}=\min \left(\frac{1}{A B}+\frac{1}{B C}, \frac{1}{A C}\right)=$

$\min (1.25+2,5)=3.25$

mean $P L=\operatorname{mean}\left(P L_{A B}, P L_{A C}, P L_{B C}\right)$

*Shortest path from $A$ to $C$ is in bold
Btwn $n_{x}=$ Fraction of Shortest Paths $x$ falls on

$$
\begin{gathered}
P L_{A B}=A \rightarrow B=\frac{1}{A B}=1.25 \\
P L_{A C}=A \rightarrow B \rightarrow C=\frac{1}{A B}+\frac{1}{A C}=3.25 \\
P L_{B C}=B \rightarrow C=\frac{1}{B C}=2 \\
B t w n_{A}=0, B t w n_{B}=1, B t w n_{C}=0
\end{gathered}
$$

Figure 7. Correlation, mean path length $(\mathrm{PL})$, and betweenness centrality $(\mathrm{BC})$ at seizure onset. For each DIV, seizure-triggered averages were computed of network correlation $(\boldsymbol{A})$, mean path length $(\boldsymbol{B})$, and betweenness centrality $(\boldsymbol{C})$. The slow buildup in mean correlation at DIV 1 transforms into a step-like increase by DIV 8 . The correlation increase results in a congruent decrease in mean path length. On DIV 1-3, when there was significant pre-ictal activity, maximum betweenness centrality peaked. In late epileptogenesis, functional connectivity abruptly transitioned from low to uniformly high, so that maximum betweenness centrality remained low. Time 0 corresponds to seizure peak. Seizure-triggered averages were computed using the 10 correlation windows preceding seizure peak. Time axis is slightly variable for reasons described in Materials and Methods, but shown here in seconds for reference. Diagrams on the right describe how each network statistic was calculated.

formation and stabilization (Dailey and Smith, 1996) have been demonstrated in organotypic slices over the time frame studied here. The most parsimonious explanation of these data is that increases in the number of recurrent excitatory synapses between pyramidal cells subserve the increases in network connectivity, seizure probability, and the rate of ictal network activation in this model. This mechanism is also supported by the reduction in activity between epileptiform events (Fig. 4E): as recurrent excitation is increased, any activity in the network is more likely to lead to pathologically high levels of network activation. This mechanism supports the neuronal homeostasis hypothesis of replacement of lost afferent and efferent connections with recurrent synapses contributes to epileptogenesis after brain injury (Houweling et al., 2005).

\section{Evolution of the epileptic network}

The incidence of epilepsy and rate of epileptogenesis following brain trauma in human or experimental epilepsy are correlated with a number of factors including developmental stage, nature of injury, and size of animal. In pediatric patients recovering from brain trauma, synaptic remodeling is driven by both normal brain development and repair of injured brain tissue (Johnston, 2009). Similarly, in organotypic slice cultures prepared from a wide age range of juvenile rodent pups, previous studies have reported increases in synaptic connectivity (Debanne et al., 1995; Dailey and Smith, 1996; Pavlidis and Madison, 1999; De Simoni et al., 2003); stabilization of initially dynamic, transient filopodial protrusions (Dailey and Smith, 1996) into dendritic spines; and epileptogenesis (Albus et al., 2013). Whether the same homeo- 


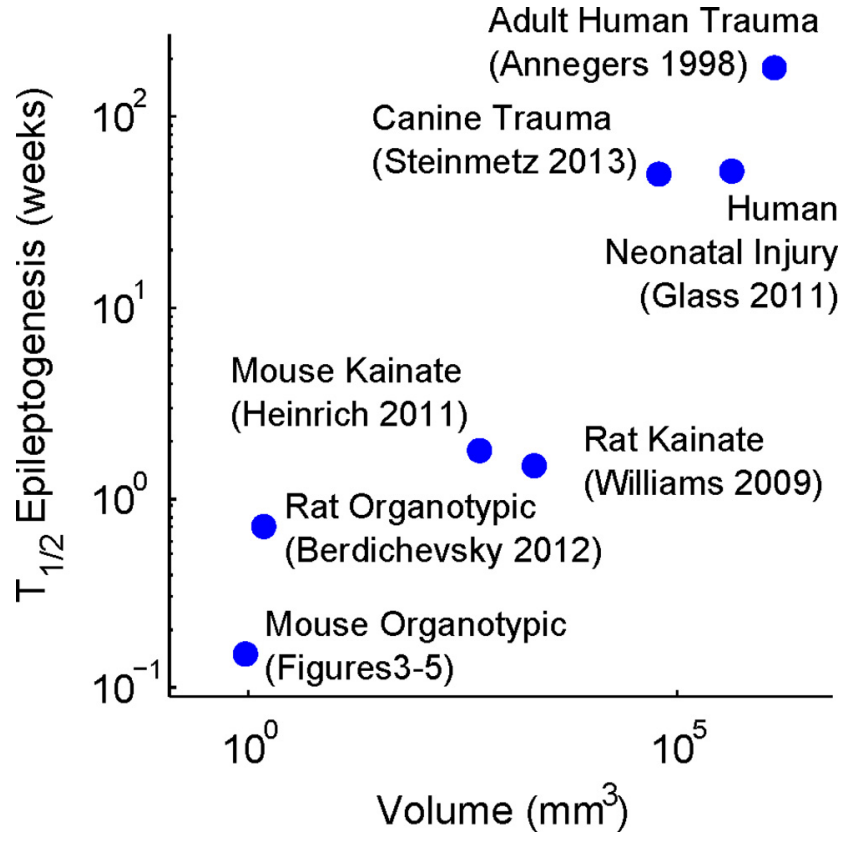

Figure 8. Latent period of post-traumatic epileptogenesis increases with brain volume. This descriptive plot demonstrates that in both experimental animal models and human epilepsy the rate of epileptogenesis is inversely proportional to the volume of brain tissue involved. Latent period data are described previously (Annegers et al., 1998; Williams et al., 2009; Glass et al., 2011; Heinrich et al., 2011; Berdichevsky et al., 2012; Steinmetz et al., 2013). Volume data from (Tajima et al., 1993; Rengachary, 2005; Badea et al., 2007; Knickmeyer et al., 2008; Kavoi and Jameela, 2011).

static mechanisms guide developmental synapse formation and recovery (or epileptogenesis) following injury remains an important, unanswered question (Avanzini et al., 2014).

If, as our data suggest, recurrent synaptogenesis underlies epileptogenesis, then a key determinant of the rate of epileptogenesis following injury is the fraction of recurrent versus nonrecurrent targets to which the injured neurons can reconnect. If neurons homeostatically scale their synapses to restore a target firing rate (Turrigiano et al., 1998), having a smaller pool of reachable synaptic targets would naturally lead to a more recurrently connected network. As a first estimate, Figure 8 shows that the rate of epileptogenesis is approximately logarithmically related to brain volume, which is used here as an estimate of nonrecurrent synaptic targets.

The rate at which neuronal activity synchronized at the onset of a seizure increased throughout early epileptogenesis (Figs. 3, 4, $5,7)$. This corresponds to an increase in long-distance correlation (Fig. 4) and to the correlation of spontaneous EPSCs in dual whole-cell recordings (Fig. 2). We interpret these data to indicate that ongoing synaptogenesis, driven either developmentally or by recovery after trauma, led to progressive shortening in excitatory polysynaptic pathways between neurons, making them shorter and more direct. A prediction of such an increase in connectivity might be that seizure probability would increase with increased excitatory connectivity in the network, but this was not observed $(p=0.0856)$. One possible explanation for this is that the interseizure interval was already as short as the typical postictal period of depression even early in epileptogenesis, so that we were not able to resolve increases in seizure probability in this model.

\section{Evolution of ictal network dynamics}

Functional connectivity in neuronal networks is quite dynamic at both the macroscopic (Hutchison et al., 2013) and microscopic
(Feldt et al., 2010) levels. Although prior research into functional network connectivity has focused predominantly on excitatory connections between neurons (Watts and Strogatz, 1998; Netoff et al., 2004; Perin et al., 2011; Markov et al., 2013), we hypothesize that changes in functional connectivity occur, at least in part, because interneurons can mask (Snyder et al., 2015) or enhance (Hamilton et al., 2013) functional connectivity among populations of principal neurons. Recent evidence suggests that there is a pre-ictal failure of inhibition (Trevelyan et al., 2006; Huberfeld et al., 2011; Lillis et al., 2012; Zhang et al., 2012), resulting in a predominantly excitatory functional network. Using windowed network analysis, we found small-world network structure during this time window in the presumed exclusively principal neuron population (Fig. 6). Furthermore, functional connectivity dynamics (i.e., the trajectory of functional network architecture as the network cycled through ictal, postictal, and interictal states) changed throughout epileptogenesis (Fig. 7). It will be interesting to see if similar measures of network connectivity dynamics can be extracted from clinical EEG data, and whether such analyses will provide useful information regarding the stage or severity of clinical epilepsy.

\section{Clinical implications}

Activation of epileptic networks

In this in vitro preparation, the rate of epileptic network activation correlated strongly with measures of network connectivity and inversely with the amount of relatively normal interictal, nonepileptic activity (Fig. 4E). One implication of these findings is that the rate of ictal activation might be useful as a gauge of seizure probability. Severity of brain injury correlates with the incidence and severity of the subsequent epilepsy (Ferguson et al., 2010; Raymont et al., 2010). The current data support the idea that these correlations may arise from loss of afferent and efferent connections and the consequent degree of recurrent connectivity in the epileptic focus. A further extrapolation might be that MRI measures of axonal sheer injury (Skandsen et al., 2010), as a biomarker of deafferentation, would correlate with later epilepsy; this has not been studied to date.

A variety of patterns of ictal onset have been demonstrated in human seizures (Geiger and Harner, 1978; Fisher et al., 1992; Yoo et al., 2014). Interhemispheric seizure propagation time has been shown to predict surgical outcome, with slow propagation corresponding to better surgical outcome (Lieb et al., 1986; Weinand et al., 1992). Similarly, the dynamics of ictal correlations determine whether seizures spontaneously terminate or continue, as in status epilepticus (Kramer et al., 2012). In line with these findings in human electrophysiology, our data demonstrate, at a cellular level, a continual decrease in seizure propagation time (Fig. 5 ) and increase in long-distance correlation (Fig. 4C,D) as epileptogenesis progresses. These data support a recently proposed computational model, which suggests that more gradual ictal onsets would be associated with lower seizure probability (Jirsa et al., 2014). This might be best addressed by an in vivo experimental study testing whether the rate of ictal activation corresponds to seizure probability.

If replacement of lost afferent and efferent connections with recurrent synapses is sufficient to induce epileptogenesis after brain injury, then inhibition of recurrent synaptogenesis should prevent this mechanism of epileptogenesis. Nonspecific inhibition of synaptogenesis with mTOR antagonists was an effective antiepileptogenic strategy in this model (Berdichevsky et al., 2013), but this strategy is likely to also inhibit functional recovery after brain injury (Fawcett et al., 2012). A more selective antiepi- 
leptic strategy would exploit the intense activation of the epileptic network, for example, by activity-dependent weakening of recurrent synapses that are activated by interictal activity (Bains et al., 1999). Although initial efforts in this regard have been unsuccessful (Hellier et al., 2009), continued efforts to identify more effective strategies of activity-dependent synaptic (or even neuronal) pruning thus might realize an antiepileptic strategy that spares functional recovery.

\section{Limitations}

The organotypic hippocampal slice preparation is a model of epileptogenesis driven by very severe brain injury, resulting in accelerated epileptogenesis. In the experiments described here, epileptogenesis was likely further accelerated, because seizure activity began at 1-2 DIV, compared with 5-9 DIV in prior studies (Berdichevsky et al., 2012, 2013). Phototoxicity associated with high-intensity multiphoton excitation of fluorescence, perturbations due to transferring slices between the $\mathrm{CO}_{2}$ incubator and the microscope stage, and transient hypocapnia may have contributed to the more rapid development of seizure activity (Albus et al., 2013). The cortical dimensions are also quite different from in vivo, with one dimension very foreshortened; this is likely to alter the pattern of recurrent synaptogenesis. Additionally, although for simplicity we have used the terms "interictal burst" and "seizure" to describe the epileptiform activity in slice cultures, slices do not have seizures in the clinical sense. Thus, while they are an experimentally accessible tool for studying neural circuit reorganization in post-traumatic epileptogenesis, organotypic slice cultures do not recapitulate all factors that may contribute to clinical epilepsy (e.g., hormonal variations, involvement of other organ systems, comorbidities, etc.).

The fluorophore used here reports primarily bursts of action potentials rather than single action potentials, and we focused on somatic calcium transients rather than dendritic activity. Thus the analyzed activity was high amplitude. The organotypic slice is prepared from young animals, so that epileptogenesis and normal developmental alterations in neuronal circuitry overlap; however, this is also the case in pediatric secondary epilepsy. Finally, the number of neurons that could be assayed was limited by the mirror servo speeds, and we were not able to identify the same neurons in sequential imaging sessions. This limited the resolution of network structure and the evolution of the role of individual neurons in spike initiation and ictogenesis.

\section{Future studies}

Our calcium imaging reflected relatively intense neuronal activity in the CA1 pyramidal cell layer, and thus was likely to miss the earliest elements of network activation. More sensitive fluorophores, larger population samples, cell type-specific reporter expression, and analysis of dendritic and axonal activity should provide additional information regarding the patterns of epileptiform network activation. Recently developed voltage-sensitive fluorescent proteins (VSFPs) hold promise for recording subthreshold activity (Cao et al., 2013; Hochbaum et al., 2014; Zou et al., 2014). This would enable experiments wherein a single neuron is stimulated and responding postsynaptic cells are mapped, rather than relying on calcium correlation-based measures of functional connectivity. The ability of high-quality VSFPs to image hyperpolarization would also facilitate mapping of functional connectivity in interneuron networks, which anatomical evidence suggests may have small-world or scale-free architecture (Buzsáki et al., 2004; Soltesz, 2006). Experiments could be further enhanced by performing chronic imaging in situ, inside the primary water-jacketed $\mathrm{CO}_{2}$ incubator, to reduce disturbance of slice cultures and enable tracking of individual neurons over many days.

\section{References}

Albus K, Heinemann U, Kovács R (2013) Network activity in hippocampal slice cultures revealed by long-term in vitro recordings. J Neurosci Methods 217:1-8. CrossRef Medline

Annegers JF, Hauser WA, Coan SP, Rocca WA (1998) A population-based study of seizures after traumatic brain injuries. N Engl J Med 338:20-24. CrossRef Medline

Avanzini G, Forcelli PA, Gale K (2014) Are there really "epileptogenic" mechanisms or only corruptions of "normal" plasticity? In: Issues in clinical epileptology: a view from the bench, Advances in experimental medicine and biology (Scharfman HE, Buckmaster PS, eds), pp 95-107. Dordrecht: Springer Netherlands.

Badea A, Ali-Sharief AA, Johnson GA (2007) Morphometric analysis of the C57BL/6J mouse brain. Neuroimage 37:683-693. CrossRef Medline

Bains JS, Longacher JM, Staley KJ (1999) Reciprocal interactions between CA3 network activity and strength of recurrent collateral synapses. Nat Neurosci 2:720-726. CrossRef Medline

Bausch SB, He S, Petrova Y, Wang XM, McNamara JO (2006) Plasticity of both excitatory and inhibitory synapses is associated with seizures induced by removal of chronic blockade of activity in cultured hippocampus. J Neurophysiol 96:2151-2167. CrossRef Medline

Berdichevsky Y, Dzhala V, Mail M, Staley KJ (2012) Interictal spikes, seizures and ictal cell death are not necessary for post-traumatic epileptogenesis in vitro. Neurobiol Dis 45:774-785. CrossRef Medline

Berdichevsky Y, Dryer AM, Saponjian Y, Mahoney MM, Pimentel CA, Lucini CA, Usenovic M, Staley KJ (2013) PI3K-Akt signaling activates mTORmediated epileptogenesis in organotypic hippocampal culture model of post-traumatic epilepsy. J Neurosci 33:9056-9067. CrossRef Medline

Berg AT, Vickrey BG, Testa FM, Levy SR, Shinnar S, DiMario F, Smith S (2006) How long does it take for epilepsy to become intractable? A prospective investigation. Ann Neurol 60:73-79. CrossRef Medline

Bernhardt BC, Kim H, Bernasconi N (2013) Patterns of subregional mesiotemporal disease progression in temporal lobe epilepsy. Neurology 81: 1840-1847. CrossRef Medline

Bonifazi P, Goldin M, Picardo MA, Jorquera I, Cattani A, Bianconi G, Represa A, Ben-Ari Y, Cossart R (2009) GABAergic hub neurons orchestrate synchrony in developing hippocampal networks. Science 326:1419-1424. CrossRef Medline

Buckmaster PS, Dudek FE (1997) Neuron loss, granule cell axon reorganization, and functional changes in the dentate gyrus of epileptic kainatetreated rats. J Comp Neurol 385:385-404. CrossRef Medline

Bushong EA, Martone ME, Ellisman MH (2004) Maturation of astrocyte morphology and the establishment of astrocyte domains during postnatal hippocampal development. Int J Dev Neurosci 22:73-86. CrossRef Medline

Buzsáki G, Geisler C, Henze DA, Wang XJ (2004) Interneuron diversity series: circuit complexity and axon wiring economy of cortical interneurons. Trends Neurosci 27:186-193. CrossRef Medline

Cao G, Platisa J, Pieribone VA, Raccuglia D, Kunst M, Nitabach MN (2013) Genetically targeted optical electrophysiology in intact neural circuits. Cell 154:904-913. CrossRef Medline

Clasadonte J, Haydon PG (2012) Astrocytes and epilepsy. In: Jasper's basic mechanisms of the epilepsies, ed 4 (Noebels JL, Avoli M, Rogawski MA, Olsen RW, Delgado-Escueta AV, eds). Bethesda, MD: National Center for Biotechnology Information.

Cohen R, Havlin S (2003) Scale-free networks are ultrasmall. Phys Rev Lett 90:058701. CrossRef Medline

Dailey ME, Smith SJ (1996) The dynamics of dendritic structure in developing hippocampal slices. J Neurosci 16:2983-2994. Medline

Dani JW, Chernjavsky A, Smith SJ (1992) Neuronal activity triggers calcium waves in hippocampal astrocyte networks. Neuron 8:429-440. CrossRef Medline

Debanne D, Guérineau NC, Gähwiler BH, Thompson SM (1995) Physiology and pharmacology of unitary synaptic connections between pairs of cells in areas CA3 and CA1 of rat hippocampal slice cultures. J Neurophysiol 73:1282-1294. Medline

De Simoni A, Griesinger CB, Edwards FA (2003) Development of rat CA1 
neurones in acute versus organotypic slices: role of experience in synaptic morphology and activity. J Physiol 550:135-147. CrossRef Medline

Dwyer JM, Duman RS (2013) Activation of mTOR and synaptogenesis: role in the actions of rapid-acting antidepressants. Biol Psychiatry 73:11891198. CrossRef Medline

Dyhrfjeld-Johnsen J, Santhakumar V, Morgan RJ, Huerta R, Tsimring L, Soltesz I (2007) Topological determinants of epileptogenesis in largescale structural and functional models of the dentate gyrus derived from experimental data. J Neurophysiol 97:1566-1587. CrossRef Medline

Dyhrfjeld-Johnsen J, Berdichevsky Y, Swiercz W, Sabolek H, Staley KJ (2010) Interictal spikes precede ictal discharges in an organotypic hippocampal slice culture model of epileptogenesis. J Clin Neurophysiol 27:418-424. CrossRef Medline

Elwes RD, Johnson AL, Reynolds EH (1988) The course of untreated epilepsy. BMJ 297:948-950. CrossRef Medline

Fawcett JW, Schwab ME, Montani L, Brazda N, Müller HW (2012) Defeating inhibition of regeneration by scar and myelin components. Handb Clin Neurol 109:503-522. CrossRef Medline

Feldt S, Wang JX, Shtrahman E, Dzakpasu R, Olariu E, Zochowski M (2010) Functional clustering in hippocampal cultures: relating network structure and dynamics. Phys Biol 7:046004. CrossRef Medline

Ferguson PL, Smith GM, Wannamaker BB, Thurman DJ, Pickelsimer EE, Selassie AW (2010) A population-based study of risk of epilepsy after hospitalization for traumatic brain injury. Epilepsia 51:891-898. CrossRef Medline

Fisher RS, Webber WR, Lesser RP, Arroyo S, Uematsu S (1992) Highfrequency EEG activity at the start of seizures. J Clin Neurophysiol 9:441448. CrossRef Medline

Fisher RS, Scharfman HE, deCurtis M (2014) How can we identify ictal and interictal abnormal activity? In: Issues in clinical epileptology: a view from the bench (Scharfman HE, Buckmaster PS, eds), pp 3-23. Dordrecht: Springer Netherlands.

Freeman LC (1977) A set of measures of centrality based on betweenness. Sociometry 40:35-41. CrossRef

Gähwiler BH (1981) Organotypic monolayer cultures of nervous tissue. J Neurosci Methods 4:329-342. CrossRef Medline

Geiger LR, Harner RN (1978) EEG patterns at the time of focal seizure onset. Arch Neurol 35:276-286. CrossRef Medline

Glass HC, Hong KJ, Rogers EE, Jeremy RJ, Bonifacio SL, Sullivan JE, Barkovich AJ, Ferriero DM (2011) Risk factors for epilepsy in children with neonatal encephalopathy. Pediatr Res 70:535-540. CrossRef Medline

Gleich DF (2009) Models and algorithms for pagerank sensitivity $\mathrm{PhD}$ thesis, Stanford University.

Goldberg EM, Coulter DA (2013) Mechanisms of epileptogenesis: a convergence on neural circuit dysfunction. Nat Rev Neurosci 14:337-349. CrossRef Medline

Gomez-Di Cesare CM, Smith KL, Rice FL, Swann JW (1997) Axonal remodeling during postnatal maturation of CA3 hippocampal pyramidal neurons. J Comp Neurol 384:165-180. CrossRef Medline

Gutiérrez R, Heinemann U (1999) Synaptic reorganization in explanted cultures of rat hippocampus. Brain Res 815:304-316. CrossRef Medline

Hamilton LS, Sohl-Dickstein J, Huth AG, Carels VM, Deisseroth K, Bao S (2013) Optogenetic activation of an inhibitory network enhances feedforward functional connectivity in auditory cortex. Neuron 80:10661076. CrossRef Medline

Heinrich C, Lähteinen S, Suzuki F, Anne-Marie L, Huber S, Häussler U, Haas C, Larmet Y, Castren E, Depaulis A (2011) Increase in BDNF-mediated TrkB signaling promotes epileptogenesis in a mouse model of mesial temporal lobe epilepsy. Neurobiol Dis 42:35-47. CrossRef Medline

Hellier JL, White A, Williams PA, Dudek FE, Staley KJ (2009) NMDA receptor-mediated long-term alterations in epileptiform activity in experimental chronic epilepsy. Neuropharmacology 56:414-421. CrossRef Medline

Heng K, Haney MM, Buckmaster PS (2013) High-dose rapamycin blocks mossy fiber sprouting but not seizures in a mouse model of temporal lobe epilepsy. Epilepsia 54:1535-1541. CrossRef Medline

Hochbaum DR, Zhao Y, Farhi SL, Klapoetke N, Werley CA, Kapoor V, Zou P, Kralj JM, Maclaurin D, Smedemark-Margulies N, Saulnier JL, Boulting GL, Straub C, Cho YK, Melkonian M, Wong GK, Harrison DJ, Murthy VN, Sabatini BL, Boyden ES, et al. (2014) All-optical electrophysiology in mammalian neurons using engineered microbial rhodopsins. Nat Methods 11:825-833. CrossRef Medline
Houweling AR, Bazhenov M, Timofeev I, Steriade M, Sejnowski TJ (2005) Homeostatic synaptic plasticity can explain post-traumatic epileptogenesis in chronically isolated neocortex. Cereb Cortex 15:834-845. CrossRef Medline

Huberfeld G, Menendez de la Prida L, Pallud J, Cohen I, Le Van Quyen M, Adam C, Clemenceau S, Baulac M, Miles R (2011) Glutamatergic preictal discharges emerge at the transition to seizure in human epilepsy. Nat Neurosci 14:627-634. CrossRef Medline

Hutchison RM, Womelsdorf T, Allen EA, Bandettini PA, Calhoun VD, Corbetta M, Della Penna S, Duyn JH, Glover GH, Gonzalez-Castillo J, Handwerker DA, Keilholz S, Kiviniemi V, Leopold DA, de Pasquale F, Sporns O, Walter M, Chang C (2013) Dynamic functional connectivity: promise, issues, and interpretations. Neuroimage 80:360-378. CrossRef Medline

Huusko N, Römer C, Ndode-Ekane XE, Lukasiuk K, Pitkänen A (2015) Loss of hippocampal interneurons and epileptogenesis: a comparison of two animal models of acquired epilepsy. Brain Struct Funct 220:153-191. CrossRef Medline

Ikegaya Y, Aaron G, Cossart R, Aronov D, Lampl I, Ferster D, Yuste R (2004) Synfire chains and cortical songs: temporal modules of cortical activity. Science 304:559-564. CrossRef Medline

Jirsa VK, Stacey WC, Quilichini PP, Ivanov AI, Bernard C (2014) On the nature of seizure dynamics. Brain 137:2210-2230. CrossRef Medline

Johnston MV (2009) Plasticity in the developing brain: implications for rehabilitation. Dev Disabil Res Rev 15:94-101. CrossRef Medline

Kavoi BM, Jameela H (2011) Comparative morphometry of the olfactory bulb, tract and stria in the human, dog and goat. Int J Morphol 29:939946. CrossRef

Knickmeyer RC, Gouttard S, Kang C, Evans D, Wilber K, Smith JK, Hamer RM, Lin W, Gerig G, Gilmore JH (2008) A structural MRI Study of human brain development from birth to 2 years. J Neurosci 28:1217612182. CrossRef Medline

Kramer MA, Truccolo W, Eden UT, Lepage KQ, Hochberg LR, Eskandar EN, Madsen JR, Lee JW, Maheshwari A, Halgren E, Chu CJ, Cash SS (2012) Human seizures self-terminate across spatial scales via a critical transition. Proc Natl Acad Sci U S A 109:21116-21121. CrossRef Medline

Lieb JP, Engel J Jr, Babb TL (1986) Interhemispheric propagation time of human hippocampal seizures. I. Relationship to surgical outcome. Epilepsia 27:286-293. CrossRef Medline

Lillis KP, Eng A, White JA, Mertz J (2008) Two-photon imaging of spatially extended neuronal network dynamics with high temporal resolution. J Neurosci Methods 172:178-184. CrossRef Medline

Lillis KP, Kramer MA, Mertz J, Staley KJ, White JA (2012) Pyramidal cells accumulate chloride at seizure onset. Neurobiol Dis 47:358-366. CrossRef Medline

Lowenstein DH (2009) Epilepsy after head injury: an overview. Epilepsia 50 [Suppl 2]:4-9. CrossRef Medline

Maglóczky Z, Freund TF (2005) Impaired and repaired inhibitory circuits in the epileptic human hippocampus. Trends Neurosci 28:334-340. CrossRef Medline

Markov NT, Ercsey-Ravasz M, Van Essen DC, Knoblauch K, Toroczkai Z, Kennedy H (2013) Cortical high-density counterstream architectures. Science 342:1238406. CrossRef Medline

McBain CJ, Boden P, Hill RG (1989) Rat hippocampal slices “in vitro" display spontaneous epileptiform activity following long-term organotypic culture. J Neurosci Methods 27:35-49. CrossRef Medline

McIntosh AM, Kalnins RM, Mitchell LA, Fabinyi GC, Briellmann RS, Berkovic SF (2004) Temporal lobectomy: long-term seizure outcome, late recurrence and risks for seizure recurrence. Brain 127:2018-2030. CrossRef Medline

McIntosh AM, Averill CA, Kalnins RM, Mitchell LA, Fabinyi GC, Jackson GD, Berkovic SF (2012) Long-term seizure outcome and risk factors for recurrence after extratemporal epilepsy surgery. Epilepsia 53:970-978. CrossRef Medline

Miles R, Wong RK (1986) Excitatory synaptic interactions between CA3 neurones in the guinea-pig hippocampus. J Physiol 373:397-418. CrossRef Medline

Netoff TI, Clewley R, Arno S, Keck T, White JA (2004) Epilepsy in smallworld networks. J Neurosci 24:8075-8083. CrossRef Medline

Newman ME (2001) Scientific collaboration networks. II. Shortest paths, weighted networks, and centrality. Phys Rev E Stat Nonlin Soft Matter Phys 64:016132. CrossRef Medline 
Noebels JL, Avoli M, Rogawski MA, Olsen RW, Delgado-Escueta AV eds (2012) Jasper's basic mechanisms of the epilepsies, ed 4. Bethesda, MD: National Center for Biotechnology Information.

Opsahl T, Agneessens F, Skvoretz J (2010) Node centrality in weighted networks: generalizing degree and shortest paths. Social Netw 32:245-251. CrossRef

Pavlidis P, Madison DV (1999) Synaptic transmission in pair recordings from CA3 pyramidal cells in organotypic culture. J Neurophysiol 81: 2787-2797. Medline

Perin R, Berger TK, Markram H (2011) A synaptic organizing principle for cortical neuronal groups. Proc Natl Acad Sci U S A 108:5419-5424. CrossRef Medline

Pitkänen A, Immonen R (2014) Epilepsy related to traumatic brain injury. Neurotherapeutics 11:286-296. CrossRef Medline

Pozo K, Goda Y (2010) Unraveling mechanisms of homeostatic synaptic plasticity. Neuron 66:337-351. CrossRef Medline

Prince DA, Parada I, Graber K (2012) Traumatic brain injury and posttraumatic epilepsy. In: Jasper's basic mechanisms of the epilepsies, ed 4. (Noebels JL, Avoli M, Rogawski MA, Olsen RW, Delgado-Escueta AV, eds). Bethesda (MD): National Center for Biotechnology Information.

Raymont V, Salazar AM, Lipsky R, Goldman D, Tasick G, Grafman J (2010) Correlates of posttraumatic epilepsy 35 years following combat brain injury. Neurology 75:224-229. CrossRef Medline

Rengachary SS, Ellenbogen RG (2005) Principles of neurosurgery. St. Louis, MO: Elsevier Mosby.

Sabolek HR, Swiercz WB, Lillis KP, Cash SS, Huberfeld G, Zhao G, Ste Marie L, Clemenceau S, Barsh G, Miles R, Staley KJ (2012) A candidate mechanism underlying the variance of interictal spike propagation. J Neurosci 32:3009-3021. CrossRef Medline

Schreiber T, Schmitz A (1996) Improved surrogate data for nonlinearity tests. Phys Rev Lett 77:635-638. CrossRef Medline

Skandsen T, Kvistad KA, Solheim O, Strand IH, Folvik M, Vik A (2010) Prevalence and impact of diffuse axonal injury in patients with moderate and severe head injury: a cohort study of early magnetic resonance imaging findings and 1-year outcome. J Neurosurg 113:556-563. CrossRef Medline

Snyder AC, Morais MJ, Willis CM, Smith MA (2015) Global network influences on local functional connectivity. Nat Neurosci 18:736-743. CrossRef Medline

Soltesz I (2006) Diversity in the neuronal machine: order and variability in interneuronal microcircuits. New York: Oxford UP.

Steinmetz S, Tipold A, Löscher W (2013) Epilepsy after head injury in dogs: a natural model of posttraumatic epilepsy. Epilepsia 54:580-588. CrossRef Medline

Stoppini L, Buchs PA, Muller D (1991) A simple method for organotypic cultures of nervous tissue. J Neurosci Methods 37:173-182. CrossRef Medline

Tajima A, Hans FJ, Livingstone D, Wei L, Finnegan W, DeMaro J, Fensterm- acher J (1993) Smaller local brain volumes and cerebral atrophy in spontaneously hypertensive rats. Hypertension 21:105-111. CrossRef Medline

Tang SJ, Reis G, Kang H, Gingras AC, Sonenberg N, Schuman EM (2002) A rapamycin-sensitive signaling pathway contributes to long-term synaptic plasticity in the hippocampus. Proc Natl Acad Sci U S A 99:467-472. CrossRef Medline

Temkin NR (2009) Preventing and treating posttraumatic seizures: the human experience. Epilepsia 50 [Suppl 2]:10-13. CrossRef Medline

Thind KK, Yamawaki R, Phanwar I, Zhang G, Wen X, Buckmaster PS (2010) Initial loss but later excess of GABAergic synapses with dentate granule cells in a rat model of temporal lobe epilepsy. J Comp Neurol 518:647667. CrossRef Medline

Trevelyan AJ, Sussillo D, Watson BO, Yuste R (2006) Modular propagation of epileptiform activity: evidence for an inhibitory veto in neocortex. J Neurosci 26:12447-12455. CrossRef Medline

Turrigiano GG, Leslie KR, Desai NS, Rutherford LC, Nelson SB (1998) Activity-dependent scaling of quantal amplitude in neocortical neurons. Nature 391:892-896. CrossRef Medline

Tyzio R, Ivanov A, Bernard C, Holmes GL, Ben-Ari Y, Khazipov R (2003) Membrane potential of CA3 hippocampal pyramidal cells during postnatal development. J Neurophysiol 90:2964-2972. CrossRef Medline

Watts DJ, Strogatz SH (1998) Collective dynamics of "small-world" networks. Nature 393:440-442. CrossRef Medline

Weinand ME, Wyler AR, Richey ET, Phillips BB, Somes GW (1992) Longterm ictal monitoring with subdural strip electrodes: prognostic factors for selecting temporal lobectomy candidates. J Neurosurg 77:20-28. CrossRef Medline

White A, Williams PA, Hellier JL, Clark S, Dudek FE, Staley KJ (2010) EEG spike activity precedes epilepsy after kainate-induced status epilepticus. Epilepsia 51:371-383. CrossRef Medline

Williams PA, White AM, Clark S, Ferraro DJ, Swiercz W, Staley KJ, Dudek FE (2009) Development of spontaneous recurrent seizures after kainateinduced status epilepticus. J Neurosci 29:2103-2112. CrossRef Medline

Yoo JY, Farooque P, Chen WC, Youngblood MW, Zaveri HP, Gerrard JL, Spencer DD, Hirsch LJ, Blumenfeld H (2014) Ictal spread of medial temporal lobe seizures with and without secondary generalization: an intracranial electroencephalography analysis. Epilepsia 55:289-295. CrossRef Medline

Zhang ZJ, Koifman J, Shin DS, Ye H, Florez CM, Zhang L, Valiante TA, Carlen PL (2012) Transition to seizure: ictal discharge is preceded by exhausted presynaptic GABA release in the hippocampal CA3 region. J Neurosci 32:2499-2512. CrossRef Medline

Zou P, Zhao Y, Douglass AD, Hochbaum DR, Brinks D, Werley CA, Harrison DJ, Campbell RE, Cohen AE (2014) Bright and fast multicoloured voltage reporters via electrochromic FRET. Nat Commun 5:4625. CrossRef Medline 